\title{
A 'putty-practically-clay' vintage model with R\&D driven biases in energy-saving technical change
}

Citation for published version (APA):

van Zon, A. H., \& Lontzek, T. (2005). A 'putty-practically-clay' vintage model with R\&D driven biases in energy-saving technical change. Algemene Economie 2. MERIT-Infonomics Research Memorandum Series No. 006 https://doi.org/10.26481/umamer.2005006

Document status and date:

Published: 01/01/2005

DOI:

10.26481/umamer.2005006

Document Version:

Publisher's PDF, also known as Version of record

\section{Please check the document version of this publication:}

- A submitted manuscript is the version of the article upon submission and before peer-review. There can be important differences between the submitted version and the official published version of record.

People interested in the research are advised to contact the author for the final version of the publication, or visit the DOI to the publisher's website.

- The final author version and the galley proof are versions of the publication after peer review.

- The final published version features the final layout of the paper including the volume, issue and page numbers.

Link to publication

\footnotetext{
General rights rights.

- You may freely distribute the URL identifying the publication in the public portal. please follow below link for the End User Agreement:

www.umlib.nl/taverne-license

Take down policy

If you believe that this document breaches copyright please contact us at:

repository@maastrichtuniversity.nl

providing details and we will investigate your claim.
}

Copyright and moral rights for the publications made accessible in the public portal are retained by the authors and/or other copyright owners and it is a condition of accessing publications that users recognise and abide by the legal requirements associated with these

- Users may download and print one copy of any publication from the public portal for the purpose of private study or research.

- You may not further distribute the material or use it for any profit-making activity or commercial gain

If the publication is distributed under the terms of Article $25 \mathrm{fa}$ of the Dutch Copyright Act, indicated by the "Taverne" license above, 


\section{MERIT-Infonomics Research Memorandum series}

A 'putty-practically-clay' vintage model with $R \& D$ driven biases in energy-saving technical change

\section{Adriaan van Zon \& Thomas Lontzek}

\section{5-006}

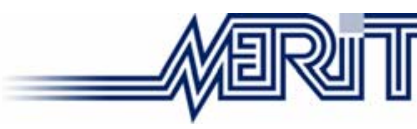

MERIT - Maastricht Economic Research Institute on Innovation and Technology

PO Box 616

6200 MD Maastricht

The Netherlands

T: +31433883875

F: +31433884905

http://www.merit.unimaas.nl

e-mail:secr-merit@merit.unimaas.nl

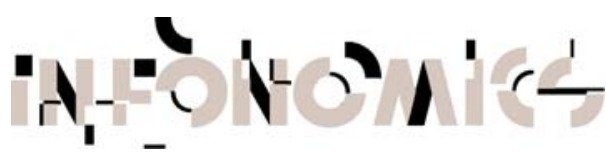

International Institute of Infonomics

c/o Maastricht University

PO Box 616

6200 MD Maastricht

The Netherlands

T: +31433883875

F: +31 453884905

http://www.infonomics.nl e-mail: secr@infonomics.nl 


\title{
A 'putty-practically-clay' vintage model with $\mathrm{R} \& \mathrm{D}$ driven biases in energy-saving technical change
}

\author{
by \\ Adriaan van Zon* \\ and \\ Thomas Lontzek ${ }^{+}$
}

(Gulpen, February 2005, second draft)

\begin{abstract}
This paper deals with the problem of tackling the adverse effect of output growth on environmental quality. For this purpose we use an intermediate sector that builds 'putty-practically-clay' capital consisting of an energy-raw capital amalgam used for final goods production. The putty-practically-clay model is a strongly simplified version of a full putty-clay model, that mimics all the relevant behaviour of a full putty-clay model, but that does not entail the administrative hassle of a full putty-clay vintage model. In addition to this, we introduce an R\&D sector that develops renewable- and conventional energy-based technologies. The allocation of R\&D activities over these two uses of R\&D gives rise to an induced bias in technical change very much as in Kennedy (1964). In the context of our model, this implies that technological progress is primarily driven by the desire to counteract the upward pressure on production cost implied by a continuing price increase of conventional energy resources. Hotelling's rule suggests that this price rise is unavoidable in the face of the ongoing depletion of conventional energy reserves. By means of some illustrative model simulations we study the effects of energy policy on the dynamics of the model for alternative policy options aimed at achieving GHG emission reductions. We identify the conditions under which energy policy might partly backfire and present some non-standard policy implications.
\end{abstract}

Key words: Induced biased, technological change, Putty-clay, Energy, Renewable resources JEL Classification numbers: E22, O31, O33, Q42, Q48

\footnotetext{
* Dr AH van Zon, MERIT/FdEWB, Maastricht University,POBox 616, 6200 MD Maastricht, the Netherlands, e-mail: Adriaan.vanZon@MERIT.UNIMAAS.NL

+ Thomas Lontzek, University of Kiel, e-mail: lontzek@economics.uni-kiel.de
} 


\section{Introduction}

There is no free energy lunch: production activity entails the consumption of energy. The ongoing growth of the level of production by the industrialised countries since the end of WWII thus has led to an ever increasing dependence of these countries on (imports of) non-renewable energy resources like oil. This dependency on imports will continue to increase in the future, as more and more oil fields are depleted and oil production becomes concentrated in just a few geographical locations. The two major oil crises in the mid 70's and early 80's have demonstrated the strong dependency of the Western world on this exhaustible resource, not only as fuel for transportation, heating and electricity generation, but also as a raw material for the production of such diverse products as clothing, fertilisers, plastics and so on. The Western way of life would look totally different without such products. In addition, in the Western world growth performance itself has become a yardstick for economic success, and so the availability of energy has become a 'condition sine qua non' for maintaining the Western way of life.

Nonetheless, our living standards are also positively affected by having a clean and healthy environment. And so growth also generates negative effects, as the increasing consumption of fossil fuels leads to more and more emissions of greenhouse gases (GHG), which in turn have an adverse effect on the environment. Even for the countries that are not growing, the emission of GHG by other countries has negative effects, as global warming may result in irreversible climate change (UNEP, 2004). And future environmental prospects are pretty bleak, for two main reasons. On the one hand, the world will continue to experience high population growth rates, mainly in developing African countries, but also in countries as China and India. This population effect will lead to an absolute increase in the total consumption of energy. On the other hand, real world output, and more in particular the average world living standard, is expected to grow, too (UN, 2005). This real wealth effect raises energy consumption in per capita terms. Both effects taken together will lead to a drastic increase in energy consumption and consequently to higher GHG emissions, ceteris paribus. As 
one can hardly demand from the developing countries to stop developing/growing, we must do our utmost best to find a mechanism that weakens the adverse effect of rising output levels on the environment, for instance by steering the global growth process in a (slightly) different direction rather than putting it in reverse.

Technological change is widely believed to be that mechanism. However, in energy/economy models, there is no consensus about even the broad nature of this mechanism, let alone about its details. Many energy models, as for example Grübler and Messner, 1998; Mabey et al. 1997 treat technical change as an autonomous process ${ }^{1}$, which leads to technical change being exogenous in these models. However, from the technical change literature (Ruttan, 2001) we know that technical progress comes from inventions and the diffusion of their application in the real world. For this reason many other economists like, for example, Dowlatabadi 1998; Carraro and Galeotti 1997; Van Bergeijk et al. 1997, have argued that technical change is driven by economic incentives, hence sensitive to (anticipated) changes in economic circumstances, and should therefore be endogenous to the model.

Applied to energy models, the concept of induced technical change as proposed by Kennedy (1964) would imply that an increase in the price of energy would invoke a higher level of energy saving R\&D activity with the purpose of raising energy efficiency. To us, this seems to be an intuitively appealing idea that is worthwhile integrating in an energy/economy context. In fact, Kennedy (1964) already discussed induced innovation. He analyzed the induced bias in technological change using a production function, which uses just capital and labor, because of the specific use he had in mind for his 'induced innovation hypothesis'. ${ }^{2}$ His main assumption is that the choice of innovating in labor or capital saving technologies depends on the weights of the respective cost shares in the unit minimum cost function. Moreover, Kennedy introduces the notion of an invention possibility frontier, describing a dynamic trade-off between labour saving inventions and capital saving

\footnotetext{
${ }^{1}$ I.e. depending on autonomous trends for example.

2 This context was to find a convincing answer to the question why technical change should be purely labour augmenting as required for steady state growth in the context of the neo-classical growth model (cf. Jones (2004)).
} 
inventions. That frontier looks very much like a production possibility frontier known from, for instance, the Heckscher-Ohlin model from the theory of international trade, and it also serves the same purpose, namely to describe all feasible and efficient combinations of labour- and capital saving inventions (or output combinations in the case of the Heckscher-Ohlin model) that one can choose from. Kennedy never provided the microfoundations of his invention possibility frontier, but in this paper we will link it to $R \& D$ activities that are driven by economic incentives, i.e. cost reduction motives, as in Kennedy's original work.

Several studies have been conducted to test the induced innovation hypothesis empirically, most recently Popp (2001) and Newell, Jaffe and Stavins (1998). Both studies provide evidence that support the induced innovation hypothesis. Popp (2001) uses U.S. patent data to test the impact of energy prices on energy saving technology. Analysing various regressions, he finds a significant strong positive correlation between energy prices and the development of new energy saving technologies. Popp concludes his work by saying that "environmental taxes and regulations not only reduce pollution...but also encourage the development of new technologies making pollution less costly in the long run."(Popp, 2001).

In our model we will distinguish between two different types of energy as they would be used in combination with other production factors (in our case capital and labour) to generate output. Hence, we will also introduce two types of innovations: those that are produced by an R\&D sector trying to find non-carbon based fuel saving production technologies and another R\&D sector that focuses on carbon based fuel saving innovations. As currently the cost share of energy from non-carbon fuels is very low, the induced innovation hypothesis would predict that the introduction of a carbon tax might in fact lead to the development of better technologies in the sector for carbon based fuels, rather than non-carbon based fuels.

A priori, the induced innovation hypothesis seems to be especially suited to describe how research activity, and hence the direction of technical change itself, will change in reaction to changes in relative user costs of energy as these would be influenced by the introduction of a carbon tax, for instance. This approach also implies that even if the renewable R\&D sector 
would be relatively efficient in increasing energy efficiency, an allocation of R\&D to the renewable energy R\&D sector does not necessarily generate the best outcome from a user perspective. For, if the share of renewable energy in total resource costs is relatively low, then the marginal gains of innovation (in terms of unit cost reduction) will be low as well, and so will be the incentives for engaging in this type of R\&D activity.

The 'induced bias in technical change' is one of the two pillars of our model. The other pillar relates to the modelling of the production function. In a recent survey Huntington and Weynat (2002) analyse several new contributions to energy modelling and the global climate change problem. They conclude that although various energy models deal with the transition to less carbon-intensive energy technologies, they suffer from the aggregate structure of the production function. Since these models do not account for individual technologies they constitute a drawback in the analysis of the transition process to carbon-free energy resources, that would have to come about by switching between specific 'technology families' implicitly defined by the use of equally specific fuels rather than by moving smoothly along an isoquant giving up the consumption of some units of a homogeneous input in favour of increasing the consumption of equally homogeneous units of another input. But in addition to this, substitution as such in the real world is not a costless exercise. The seemingly smooth movement along an isoquant entails the scrapping of specific equipment, or, if we are lucky, the retrofitting of this equipment, but also the installation of new equipment that is crucially different from the old equipment, either because it uses different inputs altogether (switches between fuels), or because it uses the same inputs more efficiently that the old equipment. The latter is captured by socalled vintage models of production, and the model presented in this paper will make use of such a vintage structure where technical change is embodied in the latest vintage of effective energy-capital, giving rise to productivity differences between individual vintages.

Vintage models come in a number of different varieties. These varieties address another critique expressed by Huntington and Weynat (2002) on recent energy models concerning the issue of new capital investments. According to the authors, almost all models assume that in making decisions 
about new capital investments, firms have complete flexibility in choosing among available technologies before (ex ante) the investment ${ }^{3}$. However, there is a discrepancy in the definition of how much the characteristic of the capital equipment can be changed after (ex post) it has been installed. This distinction translates into two types of vintage models: putty-putty and putty-clay 4 . Griffin and Gregory (1976) suggest that, unlike a putty-putty model, a putty-clay model generates a favourable framework for modelling a steady adjustment of energy use in response to a continual change in energy prices. Atkeson and Kehoe (1994) investigate the performance of the puttyclay and putty-putty models in explaining the core findings of empirical data. In some simulations they conclude that in terms of reproducing empirical results the putty-clay model clearly constitutes an improvement over the putty-putty model. Therefore, the vintage structure in our model will be of the putty-clay type.

The choice of a putty-clay structure is important on a number of accounts. First of all, a putty-clay model seems to be especially suited because energy production and energy use requires fuel specific hardware that is not easily (let alone costlessly) adjusted to changing circumstances. Secondly, policies that are meant to change the fuel-mix of energy consumption will have their full impact only after a considerable lag, as older equipments with the undesirable fuel characteristics is replaced by new equipment with the right characteristics. Thus, using putty-clay rather than putty-putty representations of reality may have serious implications for the implied timing of policy measures.

Unfortunately, full putty-clay models are tedious to handle. Instead we will be using a simplified version of a putty-clay model, called the "puttypractically-clay model' as described in more detail in Van Zon (2005). That model mimics the behaviour of a full putty-clay model, while it takes into account only 2 vintages (consisting of 'old' and 'new' equipment), and handles scrapping by means of updating the aggregate survival fraction of

\footnotetext{
${ }^{3}$ In this case it is said that capital ex ante is like soft putty (see: Phelps, 1963).

4 Following Huntington and Weynat (2002), a putty-clay formulation assumes that the original equipment cannot be modified once installed. In contrast, a putty-putty formulation assumes that capital, once installed, can also be reshaped to fit the current price situation in each time period.
} 
old-equipment, rather than explicitly scrapping the individual vintages that together constitute 'old' equipment.

The combination of both Kennedy's induced innovation hypothesis and the 'putty-practically-clay' vintage structure forms the core of our model. One finding described in this paper is that it questions the belief that a carbon tax in a model of induced technical change accelerates the substitution of non-fossil energy for fossil fuels (e.g.: Gerlagh and Wietze, 2003). It will be shown that this need not be the case. Also, since in aggregate production function models the ex post clay nature of capital is not accounted for, one possibly runs the risk of underestimating the future adjustment costs. In addition to this, one also runs the risk of doing too little too late in the face of the long policy response times implied by the embodiment of technical change in individual vintages of investment. Hence, the fact that in reality technical change is indeed largely embodied in new equipment, whereas the characteristics of this equipment are hard if not impossible to change ex post, may substantially weaken the effect of a carbon tax on the speed of transition towards non-carbon based fuel usage, as compared to a putty-putty setting, even allowing for induced/endogenous technical change. In that sense the model presented in this paper is directly relevant, if somewhat disturbing perhaps, for policy makers. For, the structure of the model explicitly addresses the consequences of having an overly optimistic view on substitution possibilities between different technologies, whereas at the same time it shows that if production and R\&D decisions are indeed driven by profit motives, then our a priori notions about the broad substitution patterns to be expected from changing relative fuel prices may simply be wrong. ${ }^{5}$ The question is whether we can afford to be wrong, given the potentially long lags between the application of policy instrument and the full impact of their effects.

The paper is further organised as follows. Section 2 presents the vintage model with two different types of capital distinguished according to

\footnotetext{
${ }^{5}$ The alternative is of course that our model is wrong. But even if this would be the case, this would obviously not imply that the standard aggregate production function model is automatically right. An aggregate production function with its usual asymptotic properties covers areas of the factor-space where we have never ventured before. We don't know as yet whether these regions are really accessible to us. That is what science is supposed to find out for us.
} 
fuel type. Section 3 describes how we combine endogenous biases in capital (hence fuel) saving technical change with this vintage model. Section 4 contains a description of the closure of the model. In section 5 we perform some illustrative simulations, while section 6 concludes the analysis and provides some policy recommendations.

\section{The vintage model}

\subsection{Introduction}

The basic idea underlying a vintage model is that the potential of technical change as an idea can only be realised in practice by first incorporating that idea in a piece of machinery and then subsequently using that machinery to produce output. While this does not deny that the ultimate source of technical change is still the idea produced by the R\&D sector, it does emphasize the fact that complementary investment has to take place in order to realise the productivity promises of new ideas. ${ }^{6}$ Phelps (1962) describes this idea as a marriage between investment and technology, where investment is seen as the carrier of technological progress. This is the so-called embodiment character of technological progress. Embodied technical change results in a heterogeneous stock of capital goods. Depending on the degree of substitution between production factors ex post, the arrival of new superior technologies may render the old ones obsolete, as in Aghion and Howitt (1992, 1998). Creative destruction is simply implied by the combination of embodiment and profit maximisation in a competitive environment.

Under the embodiment assumption, the average productivity characteristics of the total capital stock will only slowly change as new capital goods fill the gaps left by the decay and scrapping of old capital goods. In our model we will distinguish between two different technology

\footnotetext{
${ }^{6}$ Obviously, there is also technical change that comes in the form of new ideas with respect to the organisation of production, that is not as such linked to investment and that is called disembodied technical change in a vintage context. In this paper we will solely focus on embodied technical change, however, in order to simplify matters as much as possible.
} 
families, i.e. a family using carbon based fuels and one using non-carbon based fuels, each with their own vintage structure incorporating different states of a particular energy conversion technology. In order to model this, we will define aggregates of energy and capital that constitute 'effective capital'. This 'effective capital' is then used as a composite input to produce output at the vintage level. The embodiment of technical change then boils down to a change in the productivity of this 'effective capital' aggregate.

We will not allow for the possibility of substitution between the input factors after the vintage incorporating a specific technology ex post has been installed, because in practice it is hard, if not impossible at all, to change the nature of energy requirements of machinery and equipment ex post. Hence, we opt for a putty-clay vintage model (cf. Johansen 1959, Salter 1960), as stated before. There are other varieties of vintage models too, like putty-putty (Solow 1960) and clay-clay (Kaldor and Mirrlees, 1962), and even putty-semiputty models (see, for example, Van Zon (1994)), but they are less suited for our purposes (because they are putty ex post) or less general (because they are clay ex ante) than putty-clay models, or too general and therefore complicated (putty-semi-putty models) for our immediate purposes. The 'bonus' of using a putty-clay model is that it implements the idea of the irreversibility of investment decisions, as it is the case in the real world in most cases. In the putty-putty version that allows for ex post substitutability, one can simply and costlessly substitute away from factor combinations that become more costly due to changing factor prices. In a putty-clay situation, one would have to foresee these changes in factor prices ex ante, and incorporate them in the factor proportions that will be embodied in the new vintage under consideration.

In our energy model that we want use to analyse the adjustment of the economy to environmental policy measures, a putty-putty model would therefore generate unrealistic results. The reason for this is that ".. in the putty-putty model large parts of the current capital stock can be transformed into more efficient and less carbon-intensive alternatives.." (Huntington and Weyant, 2002). In the putty-clay situation this is ruled out from the outset. This implies that the productivity impact of new investment is significantly limited by older vintages of investment already there. This 
means that short run environmental targets can be reached only at the expense of relatively high adjustment costs. The clay-clay model would have been an alternative to our putty-clay model, but it causes the problem that "there is only one efficient equipment design for any one vintage," (Wan, 1971), which we feel is too limited a view on the nature of the set of production technologies available to us.

In choosing the putty-clay perspective, we are backed up by many studies that underline its empirical relevance (e.g. Griffin and Gregory, 1976 and Gilchrist and Williams, 2004).

\subsection{The ex ante situation}

The ex ante situation of our model is relatively standard. As shown in Van Zon (2005), being faced with an ex post clay situation forces entrepreneurs to take account of the present value of cumulative variable and fixed costs (but also output and sales) over the entire lifetime of a vintage. These would define optimum factor proportions constrained by some ex ante production function.

To be more precise, we assume that total capacity output at time t, i.e. $Y_{t}$, consist of the sum of part of old capacity left after technical and economic decay and the additional output generated by the new vintage. Let the decay fraction be $\omega_{t}$. In that case we have:

$Y_{t}=\left(1-\omega_{t}\right) \cdot Y_{t-1}+\Delta Y_{t}$

The level of output at the vintage level is given by a linear homogeneous CES function:

$\Delta Y_{t}=\left(\left(A \Delta K e \cdot \Delta K e_{t}\right)^{-\alpha}+\left(B \Delta L y \cdot \Delta L y_{t}\right)^{-\alpha}\right)^{-1 / \alpha}$

(2) 
where $\Delta K e_{t}$ is the marginal addition to the effective capital stock (i.e. the 'size' of the newest vintage in effective capital terms) and $\Delta L y_{t}$ is the labour employed on the latest vintage. Both $\Delta K e$ and $\Delta L y$ are input factors for the vintage installed at time t. Equation (2) states that, ex ante at least, output is a CES aggregate of effective capital and labour. The embodiment of technical change is assumed to be completely tied to effective capital, as we will explain in more detail below. $1 /(1+\alpha)$ is the elasticity of substitution between effective capital and labour at the (new) vintage level, while $A \Delta K e$ and $B \Delta L y$ are constant distribution parameters.

Effective capital corresponding to the vintage at time $\mathrm{t}$ is described by a nested CES function that describes substitution possibilities (ex ante) between carbon based and non-carbon based effective capital at the upper level, and ('virtually' non existent) substitution possibilities between raw capital and either carbon based fuels (indexed with c) or non-carbon based fuels (indexed with $\mathrm{r}$ (for 'renewables')) :

$\Delta K e_{t}=\left[\left(c_{t}^{c} \cdot x_{t}^{c}\right)^{-\rho}+\left(c_{t}^{r} \cdot x_{t}^{r}\right)^{-\rho}\right]^{-1 / \rho}$

$x_{t}^{i}=\operatorname{Min}\left(k_{t}^{i} / \kappa_{t}^{i}, f_{t}^{i} / \zeta_{t}^{i}\right) \quad, \quad i=c, r$

where $x_{t}^{c}$ is the carbon based effective capital input and $x_{t}^{r}$ is the non-carbon based effective capital input. $c_{t}^{c}$ and $c_{t}^{r}$ are the CES distribution parameters, and they can change due to $R \& D$ driven embodied factor augmenting technical change. $k_{t}^{c}$ is the amount of raw capital used to generate $x_{t}^{c}$ units of carbon based effective capital. Consequently, $\kappa_{t}^{c}$ is the unit 'raw' capital requirement of carbon based effective capital. $k_{t}^{r}$ and $\kappa_{t}^{r}$ are similarly defined for non-carbon based effective capital. Likewise, $f_{t}^{c}$ is the total amount of carbon based fuels used to generate $x_{t}^{c}$ units of carbon based 
effective capital, while $\zeta_{t}^{c}$ are the unit carbon based fuel requirements of carbon based effective capital.

The final output sector now hires carbon based and non-carbon based effective capital in proportions that can not be changed ex post: it effectively creates a vintage in accordance with equation (3.A). Because it needs to pay for the fuel and the capital services associated with each type of effective capital, it would want to do that in such a way that the total user costs of the vintage capital aggregate over the (effectively infinite) lifetime of the vintage are minimised. For that purpose we can set up the cost minimizing Lagrangian of the effective capital sector:

$\mathrm{M}_{t}=p_{t}^{c} \cdot x_{t}^{c}+p_{t}^{r} \cdot x_{t}^{r}+\lambda_{t} \cdot\left(\Delta \overline{K e}-\Delta K e_{t}\right)$

where $p_{t}^{c}$ and $p_{t}^{r}$ are the present value of the expected cost streams associated with using either type of effective capital $x_{t}^{c}$ and $x_{t}^{r}$, respectively, and $\lambda_{t}$ is the Lagrange multiplier, while $\Delta \bar{K} e$ is the required amount of effective capital at the aggregate level. Solving (4) for the levels of each type of effective capital, we find that the initial cost minimising ratio $x_{t}^{c} / x_{t}^{r}$ is given by:

$x_{t}^{c} / x_{t}^{r}=\left(c_{t}^{c} / c_{t}^{r}\right)^{1-\sigma} \cdot\left(p_{t}^{c} / p_{t}^{r}\right)^{-\sigma}$

where $\sigma=1 /(1+\rho)$ is the elasticity of substitution ex ante between the two types of effective capital. Using (3.B) in combination with (5), we find for the initial raw capital ratio and the initial fuel consumption ratio that:

$k_{t}^{c} / k_{t}^{r}=\left(\kappa_{t}^{c} / \kappa_{t}^{r}\right) \cdot\left(x_{t}^{c} / x_{t}^{r}\right)=\left(\kappa_{t}^{c} / \kappa_{t}^{r}\right) \cdot\left(c_{t}^{c} / c_{t}^{r}\right)^{1-\sigma} \cdot\left(p_{t}^{c} / p_{t}^{r}\right)^{-\sigma}$

$f_{t}^{c} / f_{t}^{r}=\left(\zeta_{t}^{c} / \zeta_{t}^{r}\right) \cdot\left(x_{t}^{c} / x_{t}^{r}\right)=\left(\zeta_{t}^{c} / \zeta_{t}^{r}\right) \cdot\left(c_{t}^{c} / c_{t}^{r}\right)^{1-\sigma} \cdot\left(p_{t}^{c} / p_{t}^{r}\right)^{-\sigma}$ 


\subsection{The ex-post situation : the 'putty-practically-clay' model}

In the absence of disembodied technical change, we have for a vintage installed at time $T$ for the ex post development over time of effective capital by type, and for that of fuel demand by fuel-type:

$x_{T, t}^{i}=\frac{I N V_{T}^{i} \cdot e^{-\mu^{i} \cdot(t-T)}}{\kappa_{T}^{i}}, i=c, r$

(7.A)

$f_{T, t}^{i}=\frac{\zeta_{T}^{i}}{\kappa_{T}^{i}} I N V_{T}^{i} \cdot e^{-\mu^{i} \cdot(t-T)} \quad, i=c, r$

It should be noted that the factor proportions of putty-clay vintages will not change ex post, apart from disembodied technical change. Hence, when variable cost per unit of output on an old vintage rises above the total unit cost on a new vintage, total profits can be maximised (or total costs can be minimised) by replacing capacity associated with old inefficient vintages by new capacity. This is known as the Malcomson scrapping condition (cf. Van Zon (2005)). However, we would like to economise on the extensive bookkeeping requirements of a full putty-clay models, as we are interested in the evolution over time of aggregate factor demand rather than factor demand at the level of each individual vintage. Therefore, we define just two vintages. The first one consists of all old equipment, and the second one is the new equipment just installed. Total output is now by assumption the sum of all output on the newest vintage, and output on that part of the old vintage that would survive the Malcomson scrapping condition explained above. To model this, we postulate a 'non-linearised' version of the ex-post production function for the old vintage.

As one recalls, ex post factor proportions in a putty-clay model are assumed fixed, implying that if the variable factor is the limiting input, then the level of output relative to capacity output will be equal to the level of input of the variable production factor relative to its corresponding capacity 
level. Moreover, as soon as the variable input reaches its capacity level, the level of output will not be able to rise any further. Consequently, the ex post production function looks as in Figure 1. For a given rental price of the variable factor, one can turn this ex post production function into a corresponding marginal cost function that is shown in Figure 2. In case of a Leontieff technology ex post, the marginal cost function is flat at a constant level that depends on the unit user cost of the variable factor here called $P V$ up to the point of full capacity utilisation.

The solid line in Figure 1 is the ex post production function. $\mathbf{q}^{\mathbf{Y}}$ and $\mathbf{q}^{\mathbf{V}}$ act like rates of capacity utilisation, as they measure actual output and input relative to capacity output and input, respectively. The marginal cost (MC) associated with using $\mathbf{q}^{\mathbf{v}}$ percent of the capacity input level of the variable factor (i.e. $\mathrm{V}^{*}$ ), will then look as in Figure 2. The horizontal part of the marginal cost curve comes from the assumption of fixed factor productivities ex post. The vertical part comes from the fact that capital becomes the limiting factor for levels of $V>V^{*}$. If $V$ rises above $V^{*}$, we find that costs still rise proportionally with $V$, while $X$ remains at $X=X^{*}$. Hence we don't get any additional output while we do have additional costs. Consequently marginal costs become infinitely high at $X=X^{*}$ implied by $V=V^{*}$.

The dotted line labelled ' 1 ' corresponds with a relatively high level of the unit total user cost on the newest vintage. Hence, profits would be maximised by retaining the old vintage and not scrapping anything. Likewise, for a relatively low level of total unit user cost as given by the dotted lined labelled '2', profit maximising entrepreneurs would scrap all old capacity replace it by new capacity. 


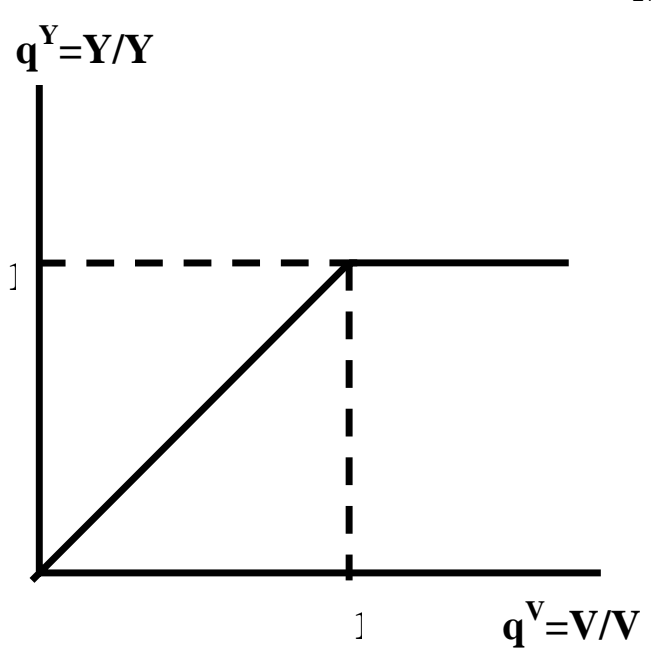

Figure 1
MC=PV.V/X

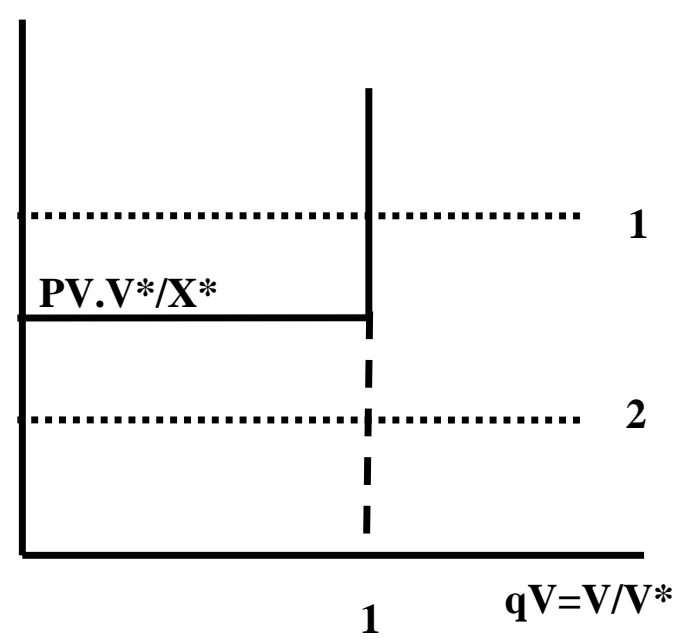

Figure 2

Obviously, for total unit costs close to PV.V*/X* a small change in $P V$ may result in the scrapping of an entire old vintage. Since in our case all old capacity is contained in just one vintage, this may result in an infinitely high price elasticity of total capacity. In order to avoid this, we may assume that there is some 'fine-structure' within our old vintage, that would generate a concave ex post production function that has the ex post production function from Figure 1 as a limiting case (i.e. as an asymptote). A function that does the trick comes from UV-analysis where it has been widely used.7 It has the form:

$q^{X}=\left(1+\left\{q^{V}\right\}^{-\beta}\right)^{-1 / \beta}$

where $\beta>0$ is a constant parameter. For ever larger values of $\beta$, the graph of equation (8) comes ever closer to the graph of the ex post production function in Figure 1. This follows immediately from the fact that for a value of $\mathrm{q}^{\mathrm{V}}>=1$ and for $\beta \rightarrow \infty$, we find $q^{X} \rightarrow 1$, whereas for $0<\mathrm{q}^{\mathrm{V}}<1$ we find that the term $\left\{q^{V}\right\}^{-\beta}>>1$, so that $q^{X} \rightarrow q^{V}$ in this case.

Using (8), the corresponding marginal cost function is given by:

\footnotetext{
${ }^{7}$ See e.g.: Sneessens and Drèze (1986) and Kooiman and Kloek (1979). This function can be shown to be a special case of the putty-semi-putty model as described in van Zon (2005).
} 
$M C\left(q^{V}\right)=P V \cdot \frac{\partial V}{\partial X}=P V / \frac{\partial X}{\partial V}=P V /\left(X^{*} \cdot \frac{\partial q^{X}}{\partial q^{V}} / V^{*}\right)=\frac{P V \cdot V^{*}}{X^{*}} \cdot\left(1+\left\{q^{V}\right\}^{\beta}\right)^{(1+\beta) / \beta}$

It should be noted that equation (10.A) only solves our problem for cases like those represented by the horizontal dotted line labelled ' 1 ' in Figure 2, i.e. for $M C>M C^{*}=P^{*} \cdot V^{*} / X^{*}$. For a case like the dotted line labelled '2', we simply postulate that the marginal cost function will be the mirror-image of (9.A), but then mirrored along the vertical through $q^{V=1 / 2}$ and the horizontal through $M C^{*}=P^{*} . V^{*} / X^{*}$. In that case we would have for $M C<M C^{*}$ :

$M C\left(q^{V}\right)=\frac{P V \cdot V^{*}}{X^{*}} \cdot\left(1-\left\{1-q^{V}\right\}^{\beta}\right)^{(1+\beta) / \beta}$

In equation (9.B), replacing $q^{V}$ in (10.A) by $1-q^{V}$ takes care of the vertical symmetry axis given by $q^{V=1 / 2}$. Changing the '+' sign into a '-' in (9.A) sign takes care of the horizontal symmetry axis through $\mathrm{MC}=\mathrm{MC}^{*} .8$ Thus, Figure 2 becomes Figure 3.

In Figure 3, the curved line (that looks like the graph of the tangent function) now represents our 'non-linearised' ex post marginal cost function. The values of $\mathrm{q}^{\mathrm{V}}$ that we can find for cases ' 1 ' and ' 2 ', for instance, will be taken to represent the survival fraction of the old vintage, further denoted by $s f_{t}$, given the fairly bold assumption that we can approximate the term $\mathrm{PV} . \mathrm{V}^{*} / \mathrm{X}^{*}$ in the marginal cost function by the average variable cost of the old vintage. In this set-up it follows that if the unit total cost of the new vintage is relatively high, then the survival fraction of old equipment will be high as well, and the other way around, as in a standard putty-clay model.

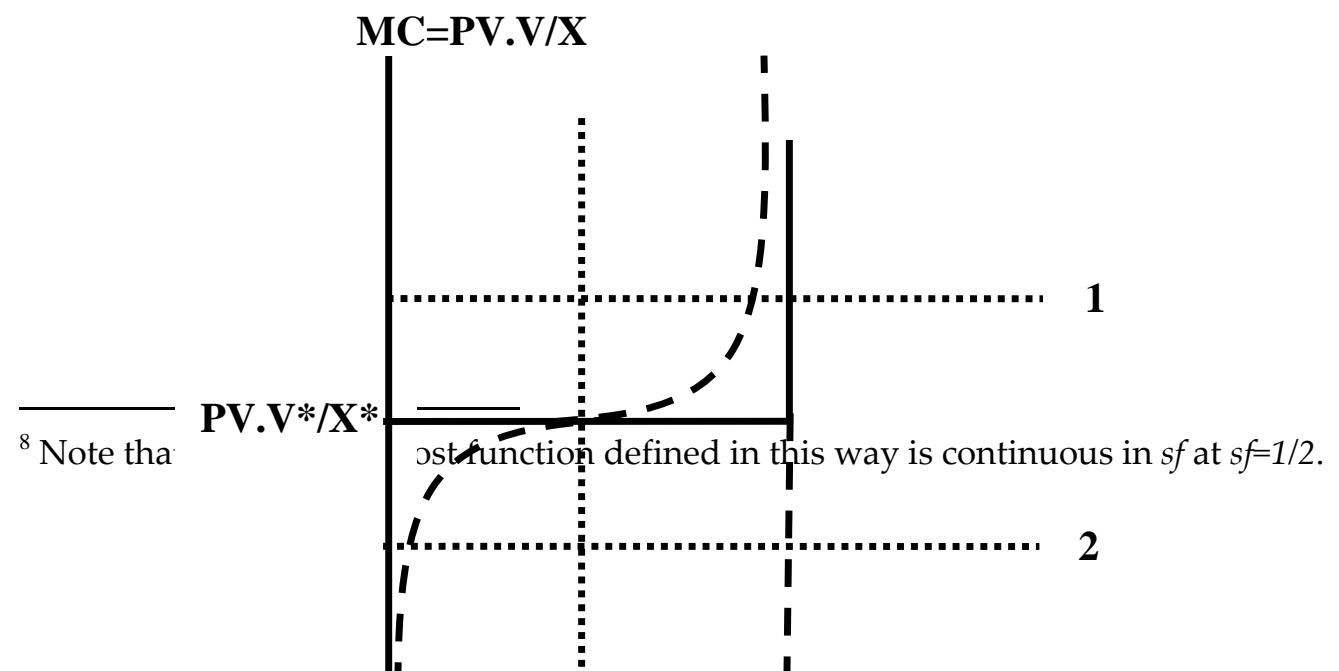


Figure 3

In fact, the value of the survival fraction can be obtained directly from (10.A) and (10.B) by equating the marginal cost function of the old vintage with unit total cost on the new vintage and then solving for $q^{V}$ (which we relabel here as $s f)$. In that case we get:

$s f=\left((u t c / m c)^{\beta /(1+\beta)}-1\right)^{1 / \beta} \quad, \quad$ utc $>m c$

(10.A)

$s f=1-\left(1-(u t c / m c)^{\beta /(1+\beta)}\right)^{1 / \beta} \quad, \quad u t c<m c$

$s f=1 / 2 \quad, \quad u t c=m c$

(10.C)

where 'utc' represents total unit cost on the newest vintage and 'mc' is the marginal variable cost on the old vintage. The average productivity characteristics of the old vintage change both due to investment in new vintages that subsequently get old, and due to technical decay and the economic scrapping of old capacity. We can obtain an estimate of the new value of the average factor coefficients of the entire capital stock, by updating the old factor coefficients in accordance with the level of investment in new capacity. Thus we get:

$F_{t}^{i} / Y_{t}=\left(\left(F_{t-1}^{i} / Y_{t-1}\right) \cdot Y_{t-1} \cdot(1-\mu) \cdot s f_{t}+\left(\Delta F_{t}^{i} / \Delta Y_{t}\right) \cdot \Delta Y_{t}\right) / Y_{t}$ 
where $F_{t}^{i}$ represents any factor used to produce output. ${ }^{9}$ With respect to total output, we now have:

$$
Y_{t}=\left(1-\omega_{t}\right) \cdot Y_{t-1}+\Delta Y_{t}=(1-\mu) \cdot s f_{t} \cdot Y_{t-1}+\Delta Y_{t}
$$

thus implicitly defining the overall decay rate as $\omega_{t}=1-(1-\mu) \cdot s f_{t}$.

Equation (11) shows how the average factor coefficients of total production capacity are a weighted average of the coefficients of old capacity and of new capacity. The bigger the volume share of new capacity in total capacity, i.e. the bigger $\Delta Y_{t} / Y_{t}$, the faster the average factor coefficients will change, ceteris paribus. ${ }^{10}$ Obviously, absolute factor use can be obtained directly by multiplying the average factor coefficients (given by (12)) with the level of aggregate capacity output (given by (13)). This also goes for the stock(s) of capital.

\section{Induced energy saving technical change}

We assume that technical change is the outcome of R\&D efforts that are endogenously determined in the model. To this end, we use a 'technical progress' production function based on that of Romer (1990). But contrary to Romer we assume that the marginal product of R\&D workers is falling with the level of R\&D effort, since we want to obtain an interior solution for the allocation of $R \& D$ workers over different types of $R \& D$, rather than bangbang reallocations of $R \& D$ workers as we would have in the case of linear R\&D functions. ${ }^{11}$ This approach has also been followed in Van Zon, Fortune and Kronenberg (2003). We postulate:

\footnotetext{
9 Obviously, (12) can be used to obtain variable unit cost of the old vintage by lagging factor coefficients by one period and then multiplying the lagged factor coefficients by the current market price of the factor under consideration.

${ }_{10}$ The inverse of this capacity share is a rough estimate of the economic lifetime of machinery and equipment.

${ }_{11}$ Romer (1990) finds an interior solution because the alternative use of high skilled workers (production in the final output sector) still has a decreasing marginal product.
} 
$\Delta c_{t}^{i}=c_{t-1}^{i} \cdot \delta_{t}^{i} \cdot\left(R_{t}^{i}\right)^{\gamma}, i=c, r$

In equation (13), $R_{t}^{i}$ is the amount of $R \& D$ labour that is engaged in carbon based and non-carbon based R\&D, respectively. Furthermore, $\delta$ and $\gamma$ are efficiency parameters corresponding to both types of $R \& D$ activities. Consequently, the growth rates of $c_{t}^{c}$ and $c_{t}^{r}$ are given by:

$\hat{c}_{t}^{i}=\delta_{t}^{i} \cdot R_{t}^{i \gamma}, i=c, r$

Equation (14) implies that the rate of effective capital augmenting technical change is increasing with $R \& D$ activities but, as we assume that $0<\gamma<1$, technological change will be characterized by diminishing marginal productivity gains from increasing R\&D efforts.

In our model, technological change is driven by the same cost reducing motivations that underlie Kennedy's induced innovation hypothesis. The idea behind this hypothesis is that $R \& D$ activities will be distributed according to the cost shares of the particular energy capital in the total effective capital costs. These shares are a direct indicator of the impact that a cost reducing innovation associated with a specific input would have on total costs.

Endogenous technical change based on Kennedy-like cost-reduction incentives has important implications for the working of the model, since in reality we observe that the renewable energy sector contributes relatively little to total energy supply. Consequently, the share of renewable energy in total energy costs is also relatively low. If the induced innovation hypothesis would hold, then R\&D activities would tend to take place primarily in the non-renewable energy sector where the potential for significant cost reductions are greater.

In fact, these cost-reduction incentives are relatively easily modelled by borrowing some of the notions present in the Romer (1990) model (but also 
in the Aghion and Howitt (1992) model), for instance. In the Romer (1990) model, R\&D labour earns a wage that is paid out of the rents that the producers of intermediate goods obtain from selling their produce to the final output sector. These rents are captured by the R\&D sector by selling the patents on their innovations. Similarly, the selling price of a patent for an improved version of a specific type of effective capital will consist of the present value of the cost savings made possible by using the improved effective capital type. Consequently, if these cost-savings are high, the wagerate that can be paid to the $R \& D$ workers engaged in finding improved effective capital types can be relatively high as well. The latter would call for a bias of R\&D effort in the direction of the activity that would generate the largest cost-reductions, ceteris paribus, thus in fact producing the kind of biased technical change described by Kennedy (1994).

In order to implement this induced bias in technical change 'story' we have to determine how technological change reduces the user-cost of effective capital. These are defined as the minimum cost of using the two Leontief constructs $x^{c}$ and $x^{r}$ as described by (3.B):

$$
p_{t}^{i}=p k_{t}^{i} / \kappa^{i}+\left(q_{t}^{i} /\left(r_{t}+\mu-\hat{q}^{i}\right)\right) / \varsigma^{i} \quad, \quad i=c, r,
$$

where $p_{t}^{i}$ are the present value of the user cost of a specific Leontief composite input per unit of the initial level of the Leontief composite input. In equation (15), $r$ is the interest rate, $\mu$ is the rate of depreciation of capital and $q_{t}^{i}$ are prices of a unit of non-renewable and renewable fuels at time $t$, respectively. $p k^{i}$ is the price of a unit of capital (which can be shown to be equal to the present value of the flow of the user cost of capital over an infinite lifetime). As mentioned before, $\zeta^{i}$ is the amount of energy resources necessary to produce one unit of the corresponding Leontief composite input. Finally $\kappa_{t}^{i}$ is the amount of raw capital used per unit of $x_{t}^{i}$.

The present value of the minimum cost of operating a vintage over an infinite lifetime is then given by: 
$\lambda_{t}=\left[\left(c_{t}^{c}\right)^{\frac{-\rho}{1+\rho}} \cdot\left(p_{t}^{c}\right)^{\frac{\rho}{1+\rho}}+\left(c_{t}^{r}\right)^{\frac{-\rho}{1+\rho}} \cdot\left(p_{t}^{r}\right)^{\frac{\rho}{1+\rho}}\right]^{\frac{1+\rho}{\rho}}$

From equation (16) it becomes apparent that an increase in the values of $c_{t}^{c}$ and $c_{t}^{r}$ would reduce the present value of operating a unit of effective capital. ${ }^{12}$ Consequently, the present value of the cost of using a new vintage of size $\Delta K e$ is then given by:

$P V C_{t}^{\Delta K e}=\lambda_{t} \cdot \Delta K e_{t}$

We can now calculate the shares $s_{t}^{i}$ of $x_{t}^{i}$ in $P V C_{t}^{\Delta K e}$. We find:

$s_{t}^{i}=\frac{p_{t}^{i} \cdot x_{t}^{i}}{\lambda_{t} \cdot K e_{t}} \quad, \quad i=c, r$

Equation (18) can be simplified using (5):

$s_{t}^{i}=\left(c_{t}^{i}\right)^{\frac{1}{1+\rho}-1} \cdot\left(p_{t}^{i}\right)^{\frac{\rho}{1+\rho}} \cdot\left(\lambda_{t}\right)^{\frac{1}{1+\rho}-1} \quad, \quad i=c, r$

We can now find out how a change in $c_{t}^{i}$ would affect $\lambda_{t}$, i.e. the present value of the user cost of one unit of a new vintage:

$$
\frac{\partial \lambda_{t}}{\partial c_{t}^{i}}=(-1) \cdot\left(\lambda_{t}\right)^{\frac{1}{1+\rho}} \cdot\left(p_{t}^{i}\right)^{\frac{\rho}{1+\rho}} \cdot\left(c_{t}^{i}\right)^{\frac{1}{1+\rho}-2}, \quad i=c, r
$$

(20)

${ }^{12}$ For reasons of simplicity we assume that the actual construction of a vintage doesn't take any resources. Only its use in producing final output does so. 
Substituting (19) into (20), we find that:

$\frac{\partial \lambda_{t}}{\partial c_{t}^{i}}=\frac{-\lambda_{t} \cdot s_{t}^{i}}{c_{t}^{i}}, i=c, r$

Based on (21), we arrive at the following conclusions. First, the right hand side is negative, implying that technological change reduces unit minimum costs. Furthermore, the higher the overall cost level, the larger will be the cost reductions. The level of technological change (as represented by $\left.c_{t}^{i}\right)$ is in the denominator of (21), implying decreasing returns in marginal cost reduction with advancing technological change. Finally, the higher the cost share of Leontief composite $i$ in total costs, the larger will be the marginal benefits from technological change in this direction. This finding is qualitatively the same as the assumption made by Kennedy (1964) regarding the importance of cost-shares as drivers of biased technical change

As in Romer (1990) or Aghion and Howitt (1992, 1998), we assume now that labour market arbitrage will govern the allocation of skilled labour over (two-) R\&D activities and final output production. For that purpose we assume that wages are equal to the marginal benefits of doing research. These benefits are given by the present value of the total vintage user cost reduction that can be attributed to the $R \& D$ embodied in the latest vintage. In fact, this total cost reduction is given by:

$$
\Delta P V C_{t}^{\Delta K e}=\Delta K e \cdot \Delta \lambda_{t} \approx \Delta K e_{t} \cdot \partial \lambda_{t} / \partial c_{t}^{i} \cdot \Delta c_{t}^{i} \approx \Delta K e_{t-1} \cdot \frac{-\lambda_{t} \cdot s_{t-1}^{i}}{c_{t-1}^{i}} \cdot c_{t-1}^{i} \cdot \delta_{t}^{i} \cdot\left(R_{t}^{i}\right)^{\gamma}
$$

where we have introduced some lagged values in the final part of (22) in order to reduce the simultaneity of the model. ${ }^{13}$ The wages received by the

\footnotetext{
${ }^{13}$ This makes it easier to solve the model numerically, while it doesn't change the long term properties of the model.
} 
R\&D workers are finally obtained by calculating the marginal 'present' value product of total cost reductions from R\&D activities:

$$
w_{t}^{i}=\partial \Delta P V C_{t}^{\Delta K e} / \partial R_{t}^{i}=\Delta K e_{t-1} \cdot\left(R_{t}^{i}\right)^{\gamma-1} \cdot s_{t-1}^{i} \cdot \gamma \cdot \delta_{t}^{i} \cdot \lambda_{t-1} \quad i=c, r
$$

Because of labour market arbitrage, all wages everywhere should be the same. In that case we find for the distribution of $R \& D$ activity over its two uses that:

$$
R_{t}^{c} / R_{t}^{r}=\varphi_{t}=\left[\frac{s_{t-1}^{c} \cdot \delta_{t}^{c}}{s_{t-1}^{r} \cdot \delta_{t}^{r}}\right]^{\frac{1}{1-\gamma}} \Rightarrow R_{t}^{c}=R_{t} \cdot \varphi_{t} /\left(1+\varphi_{t}\right), R_{t}^{r}=R_{t} /\left(1+\varphi_{t}\right)
$$

where $R_{t}$ denotes total labour available for doing $\mathrm{R} \& \mathrm{D}$ in both alternative uses. Equation (24) shows that in accordance with Kennedy's (1964) induced innovation hypothesis, relative $R \& D$ activity will depend positively on the relative shares of the respective present values of the user cost of the Leontieff composite inputs.

The relationship between the induced biases implied by the allocation of R\&D activity over its two uses is depicted in a four-quadrant diagram in Figure 4. Quadrant I in Figure 4 shows the invention possibility frontier (IPF) as in Kennedy (1964). The IPF has the standard concave shape due to the fact that $R \& D$ activities are subject to decreasing marginal products. ${ }^{14}$ Quadrant III shows the allocation of researchers in the two R\&D sectors for a given number of R\&D workers, as given by the hight of both intercepts of the solid line with angle $45^{\circ}$. At point 1 , relatively more researchers are active in the non-renewables R\&D sector. The corresponding point on the IPF mirrors this allocation. The rate of technological change in the non-renewables R\&D sector is therefore higher than the one in the renewables sector, ceteris paribus. Now suppose that the cost share of energy capital from renewable resources rises. Equation (24) tells us that the induced bias will allocate more researchers to the renewable energy R\&D sector in order to economize on the use of energy capital requiring renewable energy resources. The

\footnotetext{
${ }^{14}$ In Kennedy (1964), the concavity of the IPF had simply been assumed.
} 
reallocation of $R \& D$ workers can be seen as a downward movement along the line in Quadrant III from point 1 to point 2. At the IPF, this results in the corresponding point 2 , where $\hat{c}_{t}^{r}$ has increased and $\hat{c}_{t}^{c}$ has decreased. Thus, the rate of technical change will increase in the renewable energy sector in order to counteract the increase in the corresponding cost share.

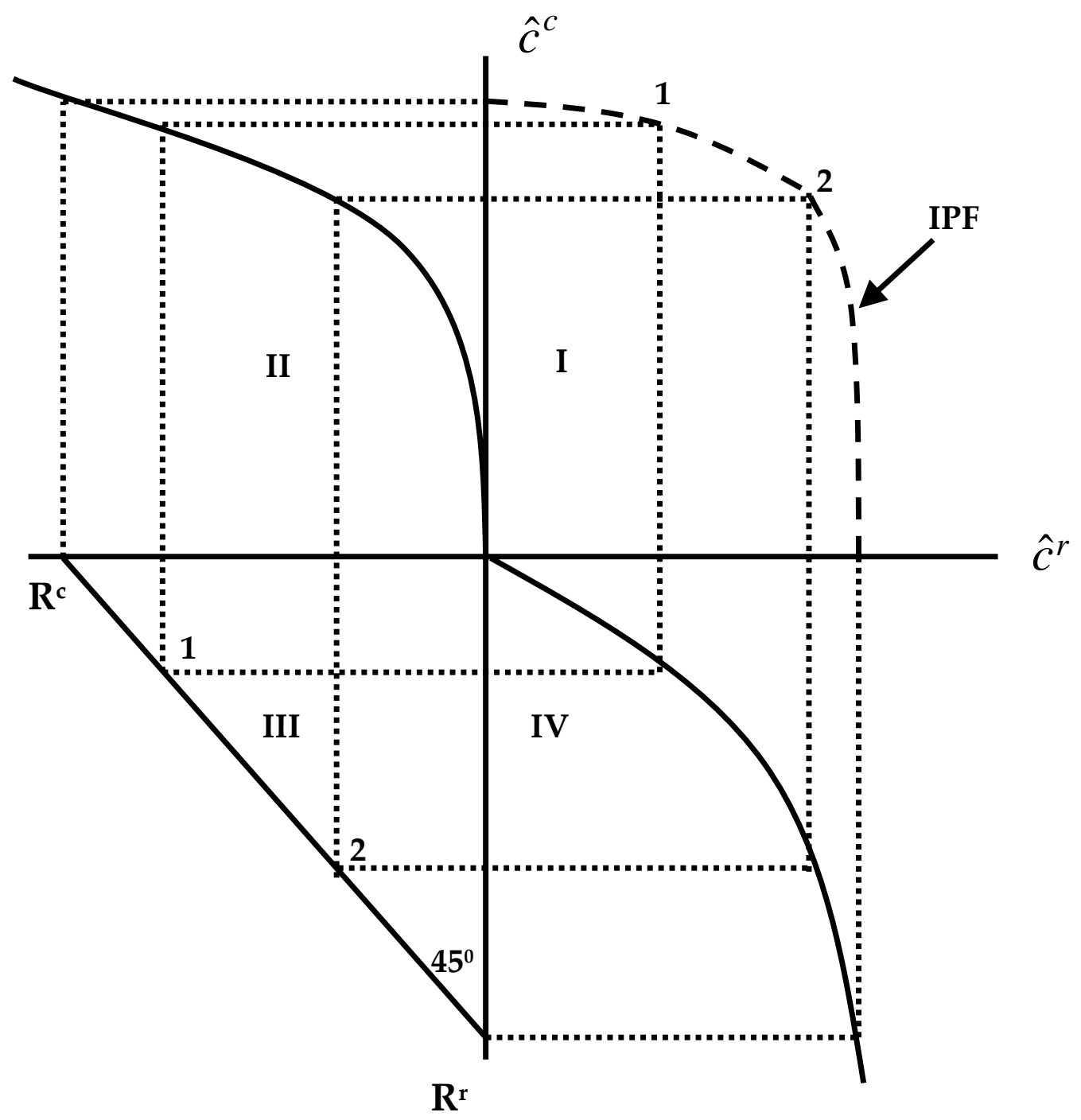

Figure 4

\section{Closing the model}

We now need to put the two main building blocks of our model together and to specify the remainder of the model. To do this, we have to decide on the size of the newest vintage, and simultaneously on the distribution of high-skilled labour over its three uses. 
As regards the first building block, it should be noted that present value cost minimisation determines the cost-minimising factor coefficients, both for the fixed factor of production and the variable factors of production (ex ante all factors are still variable...). The cost-minimising (marginal) capital coefficient then determines the level of investment given the size of the new vintage in capacity output terms. In our case, we turn this relation around. Assuming that a constant fraction of output is saved and invested, we know the size of the newest vintage in capital terms, and we can use the marginal capital coefficient to obtain the corresponding level of output. Equation (5) already provided the 'present value cost minimising' factor proportions of the newest vintage in terms of the Leontief composite inputs $x^{c}$ and $x^{r}$, while equation (6.A) provides the corresponding marginal capital ratio. Given the assumption that capital tied to the composite inputs $x^{c}$ and $x^{r}$ should completely exhaust available new 'raw' capital (i.e. savings=investment), we must have that investment in both composites is given by:

$I N V_{t}^{c}=\left(\left(k_{t}^{c} / k_{t}^{r}\right) /\left(1+k_{t}^{c} / k_{t}^{r}\right)\right) \cdot I N V_{t}$

$I N V_{t}^{r}=\left(1 /\left(1+k_{t}^{c} / k_{t}^{r}\right)\right) \cdot I N V_{t}$

$I N V_{t}=s \cdot Y_{t}$

where $s$ is the constant savings rate of the economy. Given the level of investment for each composite input, we can calculate the actual level of that input, and then, using (3.B) also the corresponding level of consumption of the different fuels.

The evolution over time of the total consumption of fuels and/or capital services is described by the combination of equations (11) and (12). That of total current emissions $E$ (as opposed to cumulative emissions) follows from the multiplication of the total use of carbon based fuels with a given emission coefficient $\varepsilon$ : 
$E_{t}=\varepsilon \cdot F_{t}^{c}$

where we have assumed that non-carbon based fuels do not cause any pollution. Therefore, in our model, the use of carbon based fuels is solely responsible for all emissions in this economy. In addition to this we have assumed that $\varepsilon$ is independent of time. From a chemical point of view this certainly holds, but from an economic point of view that doesn't have to be the case (for instance due to end of pipe abatement). For our illustrative purposes we disregard the latter, however, even though the model could be generalized to cover endogenous technical change in this direction within the Leontieff composite.

The energy vintage model will be augmented by adding two price equations for carbon and non-carbon based fuels. Again for reasons of simplicity, we assume that the growth rates of both real fuel prices are constant and positive. Moreover, the growth rate of carbon based fuels has been set equal to the real interest rate. ${ }^{15}$ The reason for that is that with a depleting stock of carbon based fuels its price must rise over the long-run in accordance with Hotelling's rule. The latter states that the growth rate of the spot price of the exhaustible resource $\hat{q}_{t}^{c}$ should be equal to the interest rate. Thus we have:

$\hat{q}_{t}^{c}=r$

Finally, the supply of labor $L S$ is taken to be exogenously determined, and during the simulations outlined below, it has been fixed at a constant level equal to 1 .

\footnotetext{
${ }_{15}$ By assumption, the real interest rate exceeds the growth rate of real non-carbon based fuels.
} 


\section{Some illustrative model simulations}

\subsection{General considerations regarding the working of the model}

Hotelling's rule plays an important role when analyzing the dynamic behavior of the energy vintage model. An increase in the price level of carbon based fuels energy resource will make its corresponding composite input more costly and therefore less desirable to use, ceteris paribus. But since the tax raises the user cost of carbon based fuels, the costs share of these fuels are likely to rise (which would be the case for a value of the 'fuel' elasticity of substitution less than one), and so there will be a tendency for the induced bias in technical change mechanism to allocate relatively more workers to the $R \& D$ sector focusing on the development of more efficient carbon based fuels technologies.

This dynamic chain of events also influences the nature and timing of environmental policies. For example, a tax levied on the use of carbon based fuels might bring about an unfavorable side effect, in the form of a reallocation of $R \& D$ labor towards the carbon based fuel $R \& D$ sector, thus in fact reducing the need to economize on the use of carbon based fuels, and therefore putting a brake on the accumulation of non-carbon based fuel technological know how. This reallocation of $R \& D$ effort is almost sure to happen ${ }^{16}$ as the main logic of the induced bias is that, if a factor of production becomes more expensive there will be contemporaneous substitution (as given by the ex ante production function for new capacity and the ex post function for old capacity) between different types of equipment using carbon- and non-carbon based fuels. In addition to this, there will also be a more fundamental change in substitution possibilities themselves, as the reallocation of R\&D efforts change the ex ante production function. This is a form of intertemporal substitution of current output for higher future output through $R \& D$ driven increases in the productivity of the scarce production factors.

\footnotetext{
${ }^{16}$ We come back to this in more detail later on.
} 
The actual values of these substitution possibilities between factors of production and the particular nesting of these factors are extremely important for the type of results one could expect. A relatively high elasticity of substitution between labor and capital, for instance, would call for strong contemporaneous substitution reactions, and hence to relatively large desired shifts in the labor/capital ratio. This would tend to raise the equilibrium wage-rate, which in turn would depress the level of both types of $\mathrm{R} \& \mathrm{D}$, that in this set-up are only geared at saving fuels, rather than all production factors. ${ }^{17}$

A faster pace of technical change also leads to creative destruction, with a corresponding loss of old capacity, that, production wise, cannot be completely compensated for by new capacity, as part of the resources tied up in new capacity have been used to counter the cost-raising effects of a fuel price rise, both through contemporaneous substitution, and through an induced reallocation of high-skilled labor between R\&D activities and final output production. This creative destruction also has a positive side-effect in that the new vintage embodying the 'new/improved' state of fuel technologies is bigger, ceteris paribus, so that the actual diffusion of the new technology takes place at a faster rate. In this context it should be stressed again that emissions per unit of aggregate output depend on the vintage composition of the capital stock too. Indeed, as we illustrate show below, this technology diffusion, as it is governed by the creative destruction process implied by the Malcomson scrapping condition, adds its own flavor to our endogenous bias in/ and endogenous diffusion of technology dish.

The rest of this section is organized as follows. In section 5.2 we present the base-run that we will use for two purposes. First it is used to illustrate the principal working of the model. Secondly, it will be the frame of reference for three different policy experiments we have conducted. These policy experiments are described in more detail in section 5.3.

\subsection{The base-run}

\footnotetext{
17 The model is however fairly easily generalised in this direction.
} 


\section{Base-run parameter-values}

In order to make the analysis less complicated, the model has been simulated by using "fake" values for the parameters as well as "fake" data for the exogenous variables and lagged endogenous variables. More extensive research has been planned to find out about the working of the model in different ((un-) connected?) regions of the parameter space. Our present aim, however, is to illustrate that the effectiveness of environmental policies in the long term may be seriously compromised by the existence of endogenous biases in technical change. If, through future research, such unwanted byeffects can be expected to occur also for regions in the parameter space that are directly relevant in practice, then obviously, (environmental) policy makers would be well-advised to incorporate these induced bias in technical change effects from the outset. Meanwhile, the only thing we want to show here and now is that problems can occur for fairly reasonable parameter

\begin{tabular}{|c|c|c|c|c|c|l|c|}
\hline Par & Value & Par & Value & Par & Value & Par & Value \\
\hline$\alpha$ & 3 & $\zeta^{i}$ & 0.1 & $\beta$ & 25 & $\hat{q}^{c}=r$ & 0.025 \\
\hline$\rho$ & 2 & $\mu$ & 0.05 & $L S$ & 1 & $\hat{q}^{r}$ & 0.020 \\
\hline$A \Delta K e$ & 10 & $\delta^{i}$ & 0.63 & $\kappa^{i}$ & 1 & $q_{t=100}^{i}$ & 0.1 \\
\hline$B \Delta L y$ & 1 & $\gamma$ & 0.75 & $s$ & 0.1 & $c_{t=100}^{i}$ & 1 \\
\hline
\end{tabular}

assumptions. That does of course not imply that no more work is needed to find an extensive empirical basis for the parameter values we have used here. The parameter values we have used are listed in Table 1.

Table 1. Structural parameter values

The way in which the base-run has been set-up is as follows. As the model uses old capacity next to new capacity, and as we use fake initial values for the stocks in order to get the simulations 'on the road', we use the first 100 time periods to get rid of initial value problems. To this end we let fuel prices remain constant until period 100, after which they are allowed to 
rise at the percentage rates provided in Table 1 . Then in period 125, we allow for the possibility of endogenous biases in technical change, whereas up to period 125, we had set the total level of R\&D labor equal to zero, thus effectively leading to a zero rate of fuel saving technical change up to that point in time. The policy experiments explained in more detail in section 5.3, will also start in period 125, and will end in period 150, after which we have 50 periods until the end of the simulation period during which we can see whether (some of) the temporary policy effects will persist or not.

\section{Base-run outcomes}

Using both the parameter-values and the simulation procedure outlined above, we have obtained the development over time of a number of important variables. These are the level of output itself (labeled Y), the share of new capacity in total capacity (labeled DY_OVER_Y), the survival fraction of old capacity, labeled $S F$, the number of R\&D workers in carbon based and non-carbon based R\&D (labeled $R C$ and $R R$, respectively), and total current emissions (labeled EMISSIONS) and its percentage growth-rate (labeled GEMISSIONS).

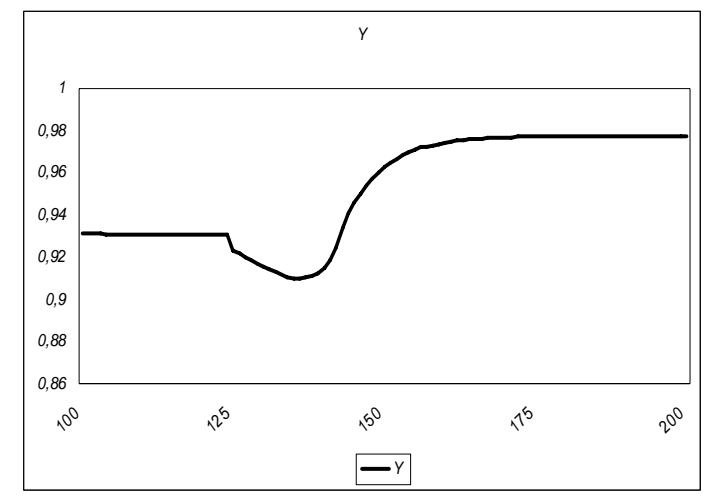

Figure 5

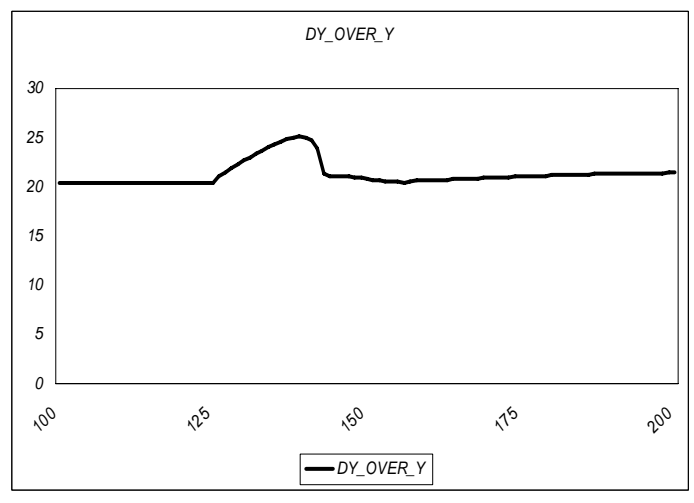

Figure 6

Figure 5 shows the level of output Y. We see that the lack of (labor saving) technical progress in combination with a fixed saving rate leads to a constant level of output until period 125, from which time R\&D based technical change can take place, as depicted in Figures 7 and 8. 


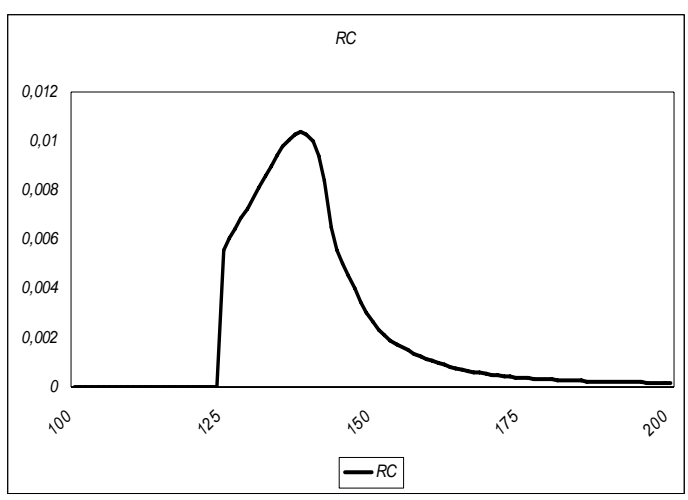

Figure 7

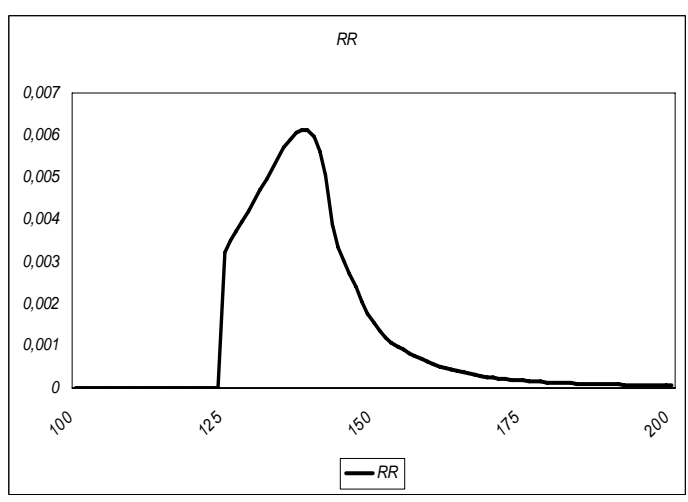

Figure 8

It is clear that technical change does indeed take place from period 125. The level of $R \& D$ peaks before period 150 and then is reduced to very low levels up to the end of the simulation period. This is due to the fact that increased $R \& D$ activity can not actually eliminate the impact of the continuing rise of carbon based fuel prices on the user cost of (carbon based fuel using) capital, and so leads to an ever increasing demand for labor, that is increasingly drawn from the $R \& D$ sector. However, in period 125, something else entirely is happening. At that moment in time, when the rates of fuel saving technical change rise relatively quickly, we see the creative destruction effects of this surge in technical change. For, as Figure 6 shows, in the short term, output actually drops below its initial level, before it starts rising again, once all the old capacity has been discarded.

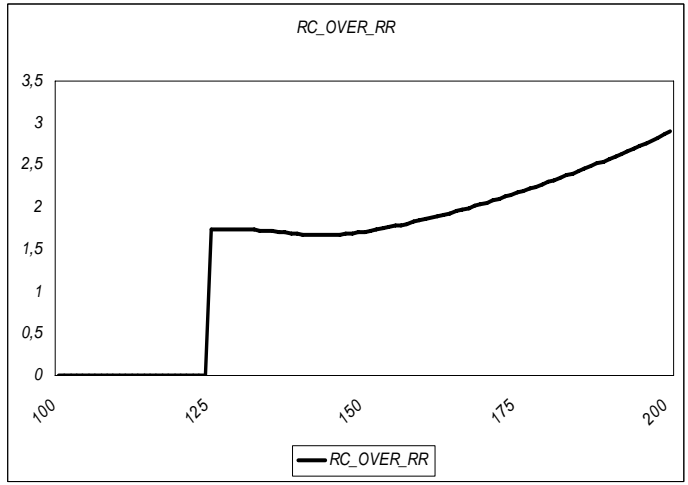

Figure 9

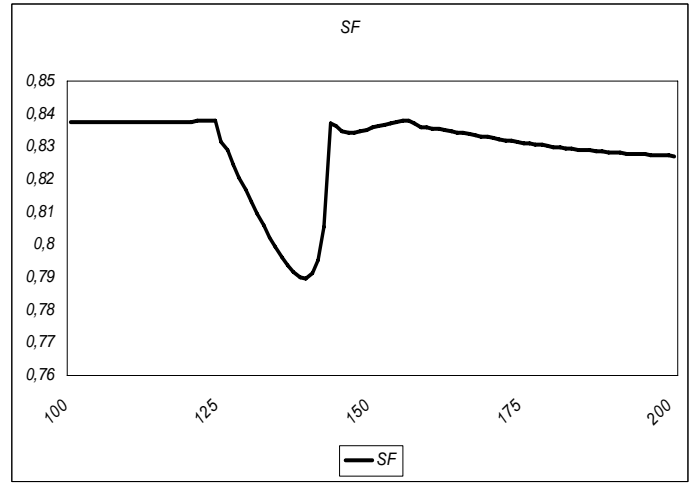

Figure 10

The reduction in economic lifetime implied by faster technical change is illustrated more directly in Figure 10, showing the survival fraction of old equipment. That fraction drops by about 5 percentage points, and once all 
equipment has been renewed, the survival fraction return to its previous level, and from about period 160 onwards, starts falling very slightly for the rest of the experimental period. The latter is due to the fact that technical change is still taking place, but now at a relatively low rate, since only little $R \& D$ is done. In addition to this, the average characteristics of the old capital stock have now come closer to the new capital stock, thus leading to a smaller difference between unit total cost on the new vintage and marginal variable cost on old equipment, and hence to lower (but still positive) rates of scrapping, ceteris paribus.

Figure 9 shows that even as both levels of R\&D are positively affected by the continuous rises in fuel prices, carbon based R\&D activity is higher than non-carbon based activity, since $R C_{-} O V E R \_R R$ does indeed measure the ratio of employment in both $R \& D$ sectors. We see that the ongoing increase in the relative price of carbon based fuel, does indeed bring about an ongoing increase in this employment ratio, even though the absolute levels of employment are falling after having reached a peak at period 135 or thereabouts.

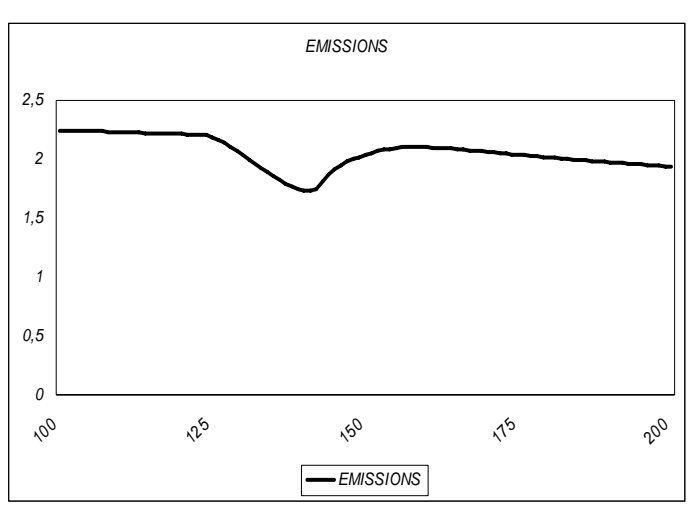

Figure 11

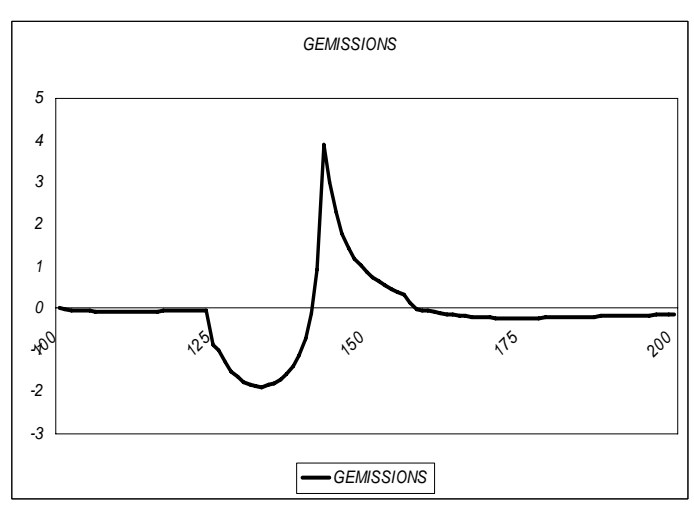

Figure 12

Figures 11 and 12 show what happens to emissions. They reach a minimum around period 135, when output is at an all-time low, and R\&D is at an all-time high. When economic lifetime picks up again, as indicated by the drop in DY_OVER_Y and the rise in $S F$, emissions are picking up too, but a slightly negative trend sets in from about period 160. This is due to both contemporaneous substitution between labor and capital, and fuel saving technical change. The net long term effect on output is that it has risen 
above its initial level, remaining roughly constant until the end of the simulation period at that higher level, whereas emissions are falling until the end of the period from a peak level that is actually below the initial level when endogenous technical change sets in. Hence R\&D generates an environmental dividend in this set-up that comes from both contemporaneous and intertemporal substitution (trading output now for more efficient production methods through $R \& D$ in the future).

\subsection{Policy experiments}

In this section we describe the results of four different experiments. These are:

1. a carbon-tax on the carbon based fuel price of 1 percent, that is recycled as a subsidy on the non-carbon based fuel price;

2. a carbon-tax on the carbon based fuel price of 0.1 percent, that is recycled as a subsidy on the non-carbon based fuel price;

3. a carbon-tax on the carbon based fuel price of 0.1 percent, that is recycled as a subsidy on $R \& D$ wages on non-carbon based energy technologies;

4. a carbon-tax on the carbon based fuel price of 0.1 percent, that is recycled as a subsidy on $R \& D$ wages on carbon based energy technologies.

Experiment 2 is a small prelude to experiments 3 and 4 . We want to show that the qualitative results do not change with different values of the tax rate. The reason to show this is that if we want to recycle the tax revenues from taxing the use of carbon based fuels in the form of a subsidy to $R \& D$ wages, then we need to have a very low tax rate, because the $R \& D$ wage sum is relatively low (roughly 1-2 percent of the total wage-sum). And even though fuel costs in final output production are fairly low in comparison with labor costs at the aggregate level, they are still about an order of magnitude higher than the total wage-sum of R\&D workers. 
In experiment 3 we want to show how a recycling of the tax revenues in the form of a subsidy on non-carbon based R\&D costs would affect output and emissions. The tax rate is low in absolute terms for the reasons outlined above. Nonetheless, experiments 1 and 2 generate qualitatively similar results, suggesting that also for a higher tax rate the same kind of results could be obtained. ${ }^{18}$ In order to be able to make a 'fair' judgment about the most effective way of recycling the tax revenues, we also perform experiment 4 , in which the revenues are recycled in the form of a subsidy to workers in the carbon based fuel technology R\&D sector.

In the Figures below, we show how the results of experiments 1-4 compare with the results from the base-run. We show all experiments in each Figure. Relative percentage deviations from the base-run are denoted by adding the post-fix ' $R$ ' (for 'relative') to a certain variable name. Absolute deviations from the base-run values have post-fix ' $\mathrm{A}$ ' (for 'absolute') added to their name. That name also contains the relevant 'experiment number' (i.e. 1-4) just before the post-fix. We continue with a description of the outcomes of each experiment outlined above.

\section{Experiment 1}

Figures 13 and 14 show what happens tot total and to marginal output (the latter as a fraction of total output). In experiment 1 , we see that output in the short term is positively affected. In the long term, however, output falls slightly below the base-run level. The reason is, quite unexpectedly perhaps, that R\&D activity actually falls in both sectors, as is shown in Figures 15 and 16. However, as expected and as shown in Figure 17 , the ratio of carbon based fuel R\&D activity relative to non-carbon based fuel R\&D activity increases, as one would expect from Kennedy's induced innovation hypothesis.

\footnotetext{
18 That is, apart from the possibility that the subsidy would result in negative wage-costs, in which case the model numerically breaks down. That is why we have ended up using such low tax rates, having had too little time to do a more extensive search for other parameter-sets that also generate feasible results. This is on 'future research' list.
} 


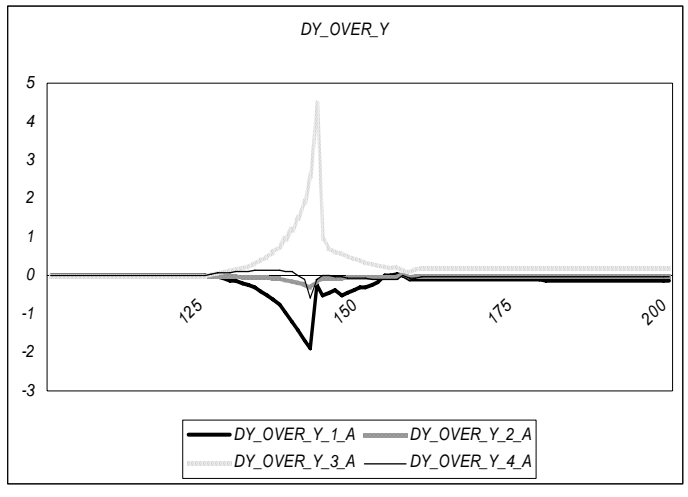

Figure 13

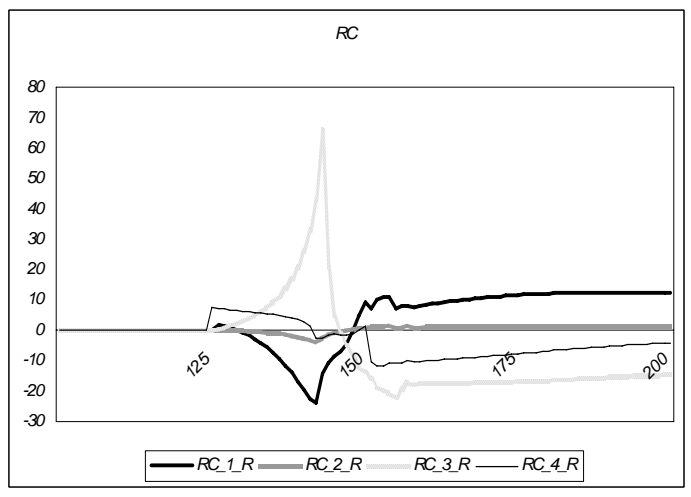

Figure 15

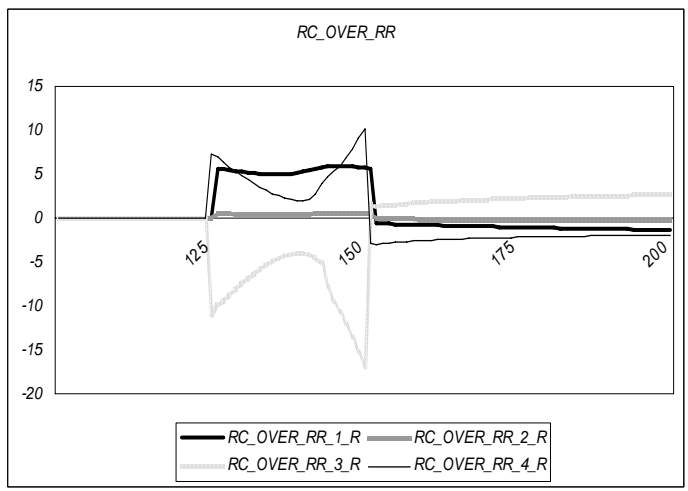

Figure 17

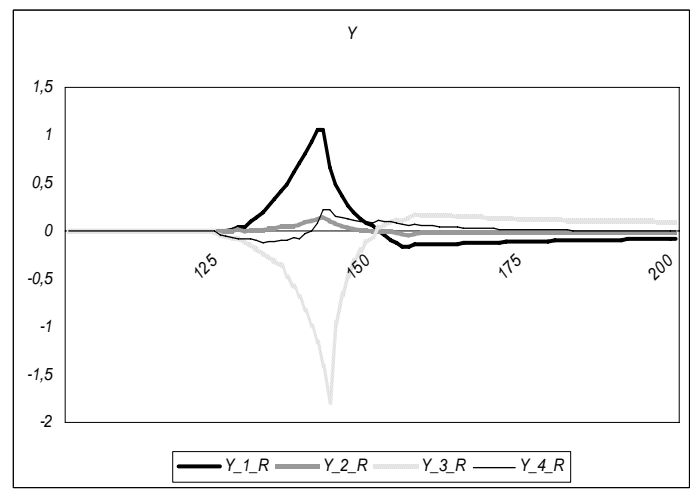

Figure 14

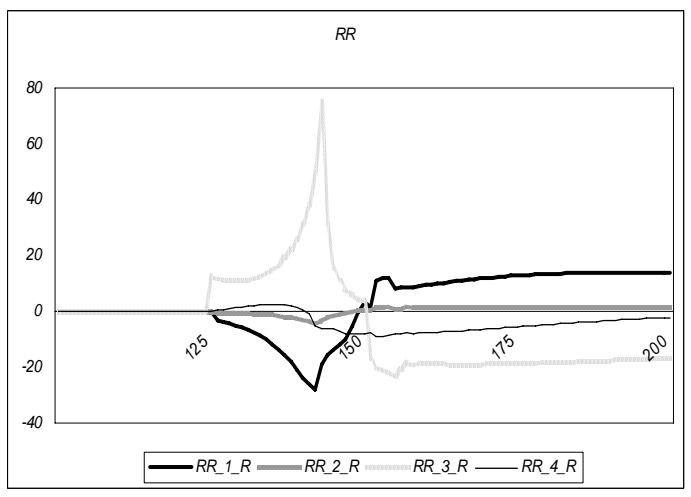

Figure 16

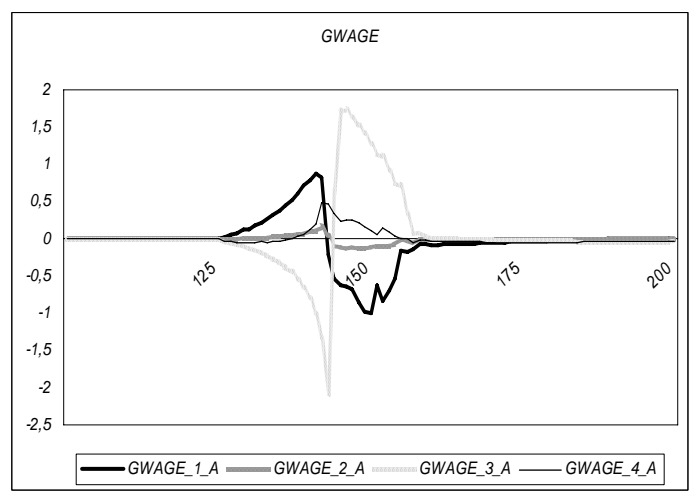

Figure 18 


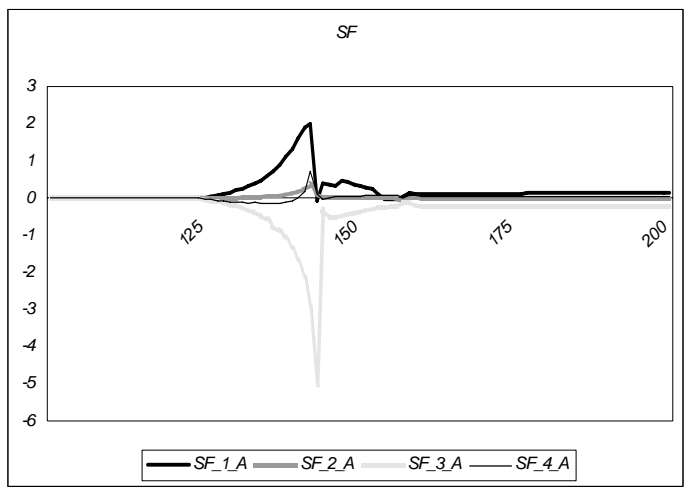

Figure 19

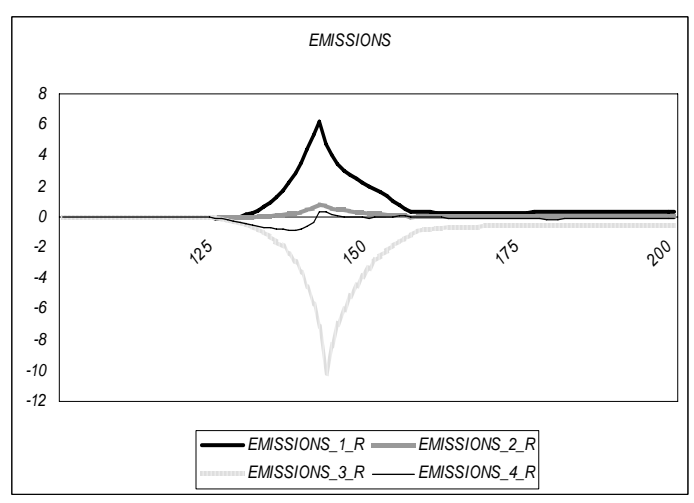

Figure 20

The reason for this somewhat unexpected sequence of events is that the cost raising effects of the carbon tax increases the user cost of carbon based fuel using capital by so much that the user cost of capital of the new vintage rises, and with that total unit cost on the new vintage. This has two major consequences. First economic lifetime increases, as indicated by the rise in the survival fraction $S F$ in Figure 19. This has immediate consequences for the emission-level that rises above the base-run, because more old capacity is now used that is in addition less clean than the baserun capital stock.

It should moreover be noted from Figure 13 that the rise in output levels is a temporary phenomenon, as in the long term, after the tax is removed in period 150, output quickly drops below the base-run level. The reason is that the high wage growth caused by the rise in carbon based fuel prices that makes labor more attractive as a substitute for aggregate capital, has led to a lower demand for R\&D labor on two accounts. First because wages determine the cost of doing $R \& D$, while secondly due to the cost raising effects of the carbon tax, the user cost of capital has risen, making for a lower demand for (aggregate) capital, hence for a lower actual value of cost reducing innovations (cf. equation (23)). These two effects obviously lead to a fall in the level of R\&D for non-carbon based fuels. These effects are so strong that they also lead to a fall in the level of R\&D for carbon based fuels, even though the incentive for doing that kind of R\&D has strengthened. Both levels of $R \& D$ fall therefore, but $R^{c}$ less than $R^{r}$, see also Figure 17 . So, the 
contemporaneous substitution effect outweighs the intertemporal substitution effect in this case.

Still, technical change is taking place, although at a lower rate than before, as shown in Figures 21 and 22. The latter Figures are particularly interesting, since they show that whereas $R \& D$ activity in the non-carbon sector drops from the beginning in period 125, the level of $R \& D$ in the other sector rises slightly above that in the base-run, for just a few periods starting in period 125. In the long run, though, the rates of technical change are slightly above their base-run values. It should be noted that in the long run, output is slightly lower while emissions are slightly higher than in the baserun, the latter being due to the fall in the rate of technology diffusion as indicated by the fall in the relative share of new capacity in total capacity next to the survival fraction of old capacity.

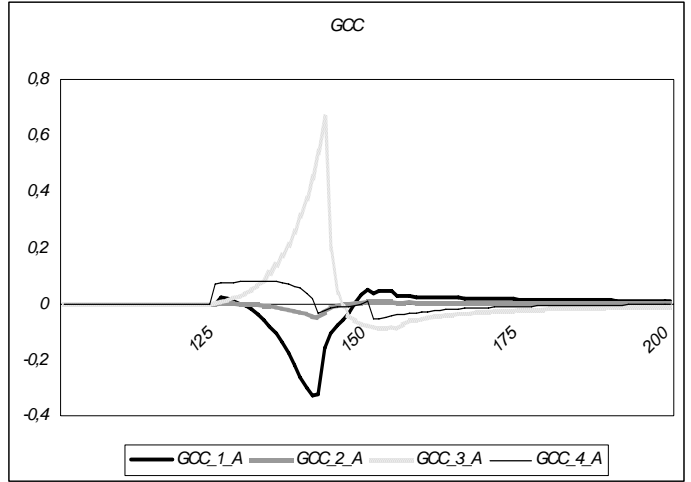

Figure 21

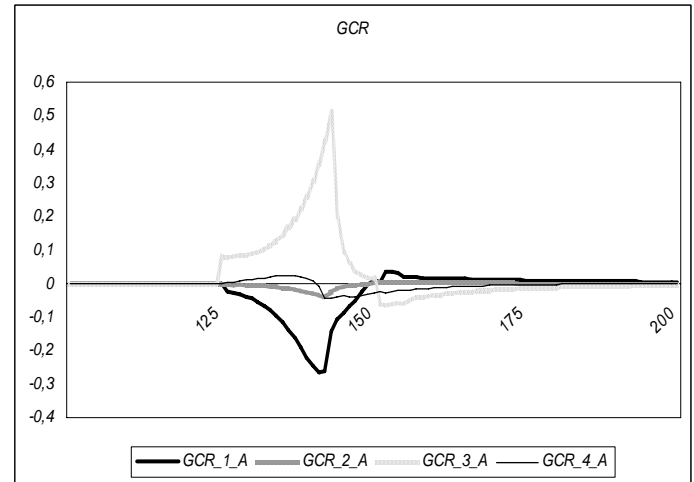

Figure 22

\section{Experiment 2}

The results for this experiment, which is the same as experiment 1 , only the tax rate is 0.1 percent instead of 1 percent, indicate that that the timepattern of the variable changes is the same as in experiment 1. Only the size of the changes is correspondingly smaller. This means that, apart from numerical difficulties that may arise for negative wages and so on, the scale of things does not matter (much) for the qualitative behavior of the model. As we are presently interested in just the qualitative behavior of the model, this allows us to turn to experiments 3 and 4 . 


\section{Experiment 3}

In this experiment, we recycle the tax revenues obtained from a 0.1 percent consumption tax on the price of carbon based fuels in the form of a subsidy on wages in the non-carbon based fuel technology R\&D sector.

In this experiment we observe a drop in the level of output as soon as the experiment starts. This is due to technology induced scrapping (the survival fraction $S F$ goes down by quite a bit). It should be noted that this short term drop in output is followed by a long term rise in the level of output that is actually above the base-run level. This reflects the intertemporal trade off mentioned earlier, between output now and future output through increased R\&D efforts. We see that, contrary to the previous experiments, the levels of R\&D activity in both sectors are positively affected. The carbon based fuel technology R\&D sector experiences a rise in activity (relative to the base-run) because there is now more scope for R\&D based cost reductions, whereas non-carbon based fuel technology R\&D activity is influenced positively through the wage-subsidy. However, R\&D does shift in favor of non-carbon based fuels, as is apparent from Figure 17.

It should be noted that the induced scrapping effect of the acceleration in the rate of fuel saving technical change wears out after a while, and when all inefficient equipment has been scrapped, general $R \& D$ activity falls again, thus mitigating the creative destruction effects of technical change and so reversing the initial drop in the growth rate of output. This leads to a rise in the growth rate of wages. The removal of the tax and the wage subsidy in period 150 when $R \& D$ activity is already low does changes the situation only very little.

One of the effects of this experiment is that the wage-sum in the final output sector (which accounts for almost 100\% of the total wage sum, since total R\&D sector employment is so low (certainly after period 150)) is permanently higher in the long term. This is due to the fact that the vintage capital stock has become more efficient on the one hand, while on the other hand DY_OVER_Y is also structurally higher. This indicates that the rate of diffusion of technical change through new investment must be higher too. So output can rise on two accounts: first because individual vintages become more productive (see Figures 21 and 22) and secondly because the capital 
stock is younger on average than in the base-run. With roughly the same labor resources as in the base-run available for producing final output, the quality increase of the capital stock allows for a rise in final output labor productivity, and hence to a rise in the level of final output itself. Finally, we notice that even as output grows above its base-run level in the long term, emissions remain below their base-run level, again due to the quality increase of the capital stock.

\section{Experiment 4}

In this experiment we raise a 0.1 percent consumption tax on the price of carbon based fuels and recycle that in the form of a wage subsidy on carbon based fuel technology R\&D. There are a number of remarkable results to be seen. First, even though the parameters of the R\&D sectors are all the same, and even though this also applies to tax revenues, the impact of this experiment on the model variables is far smaller than in experiment 3. We also find the same reaction pattern over time, except for the timing of the sign-reversals of the deviations from the base run. That comes slightly earlier in experiment 4 than in experiment 3 . Third, we find no significant effect on emissions, relative to the base-run. The latter is caused by two things. First, increased carbon based fuel R\&D changes the technology embodied in the latest vintage in favor of carbon based fuels, while secondly the rate of diffusion of technical change is hardly changed at all.

\section{Summary and Conclusion}

In general one can say that energy-related $R \& D$ activities, which increase energy efficiency by generating technological change, can be an effective way to reduce the emissions of GHG. In this context, technological change allows for the potential coexistence between rising output levels and moderate emissions of GHG as the direct positive impact of output growth on emissions becomes weaker.

According to new growth theory, technical change is mainly the result of successful R\&D activities that are driven by economic incentives. But, in case market forces do not generate the required type and pace of technical 
change, the application of environmental policies, such as a carbon taxes and subsidies would need to be considered, for instance by countries that are obliged to achieve some short- or medium run environmental targets, as e.g. the Kyoto targets. Nevertheless, the implementation of a carbon tax is associated with the risk of pushing $R \& D$ in the wrong direction. As the induced innovation hypothesis implies, a carbon tax will increase the user price of carbon based fuels. This in turn will create the incentives to engage in developing a better technology that will compensate at least part of the price rise. As this form of $R \& D$ will take place in the sector for carbon based fuel technologies, finding the structural solution to the environmental problem will only be postponed. It will not be attacked directly, since no direct incentives have been created to intensify the use of non-carbon based fuels. In addition, if technical change is largely embodied, then the existing capital stock using carbon based fuels represents large sunk costs, meaning that it cannot be reshaped and substituted for by other inputs, and that it will only gradually be put out of action, thus effectively limiting the impact of policy measures to investment margin. In order to achieve some preset policy targets then may imply a fairly long time path for the application of the corresponding policy instruments. The 'control problem' that comes to mind is that of steering a fully loaded super tanker into the harbor of Rotterdam. Way before Rotterdam can actually be seen, the navigator has to apply the 'brakes' in order not to miss the target. This is due to the momentum associated with a large moving mass. The existing capital stock also provides such a mass. And the implications for policy makers are qualitatively the same: don't wait applying the brakes until it is too late.

The objective of this paper has been to investigate how an environmental policy could be implemented in order to deal with the environmental problems outlined above. For this purpose, an energy model has been developed which distinguishes between an R\&D sector developing non-carbon based fuel using technologies, and a sector that develops carbon based fuel using technologies. The model presented in this paper combines two major building blocks, i.e. Kennedy's 'induced bias in innovation hypothesis' and a simplified representation of a putty-clay vintage model called a 'putty-practically-clay' model. We have used a nested CES 
production function to describe ex ante substitution characteristics between labor and effective capital. The latter consists of Leontieff composite inputs of 'raw' capital and carbon- and non-carbon based fuels. We then introduced two R\&D sectors that may change the quality of the equipment making use of either fuels. We assume decreasing marginal product of R\&D workers, and can so obtain an interior solution for the allocation of $R \& D$ effort, that depends directly on the cost-shares of the composite inputs in the total user cost of effective capital. This is directly in line with Kennedy's hypothesis, but in our model it results from more 'fundamental' assumptions than in Kennedy (1964). In reality the cost share of non-carbon based fuels is very low, and the introduction of a carbon tax might in fact lead to the somewhat perverse effect of the development of better technologies in the sector for carbon based fuel using technologies. The other main building block is the putty-practically-clay model that has the flavor of a full putty-clay model, but it lacks the extensive bookkeeping requirements of a full vintage model, as we distinguish between just two vintages, i.e. an old one and a new one. The distinction between old and new capital is important, because technical change needed to save us all from ever increasing environmental problems does unfortunately not fall as manna from heaven. And even if technical change itself would be a free good (which new growth theorists deny that it is), productivity increases can only be realized through investment in new equipment that incorporate (or embody) the new ideas that underlie the potential increases in productivity in the first place. So there are investment costs involved in benefiting from technical change, apart from the costs of obtaining the right to incorporate these new ideas in equally new equipment.

Using a simulation version of the model that combines Kennedy's induced bias in innovation hypothesis with the putty-practically-clay model we have analyzed its dynamics when a carbon tax is introduced. The experiments that we have performed show that the reduction in emissions depends very much on the way in which the tax revenues are recycled. When the recycling takes the form of a subsidy on $R \& D$ wages in the non-carbon based fuel technology R\&D sector, emissions in the long term are below their base-run level. But when the tax revenues are recycled in the form of a wage subsidy for the carbon based R\&D sector, emissions are not reduced. If the 
revenues are recycled in the form of a subsidy on the consumer price of noncarbon based fuels, long term emissions are not reduced either, even though long term output is slightly below its base-run level. The reason is that the subsidy on the consumer price of non-carbon based fuels leads to more contemporaneous substitution, but also lower cost-reduction incentives to engage in non-carbon based fuel saving technical change. In addition, the relative lack of technical change calls for an expansion of the economic lifetime of equipment, thus in effect reducing the fuel-consumption quality of the capital stock. The latter result goes directly against the existing belief that a carbon tax in a model of induced technical change accelerates the substitution of non-fossil energy for fossil fuels. For the parameter-set we have used, we can state that this belief is at least incomplete, and maybe even wrong in the short term, while it is certainly wrong in the long term. The reason for the potential lack of short term performance of such a policy is that a change in the rate of technical change also changes the lifetime of equipment. This in turn may leads to potentially large changes in the level of investment which in turn provides an additional change in incentives to do $R \& D$, and may so have unwanted long term effects. The reallocation of $R \& D$ activity in the direction of carbon based fuel saving technical change is responsible for the lack of long term performance of such a tax policy.

We have seen in experiment 1 in particular, where the levels of R\&D activity actually dropped below the base-run levels, that the feedback from technical change itself to the economic lifetime of equipment becomes a very important factor in determining the overall level of R\&D activity. The reason is that the latter also depends directly on the level of investment, since a higher level of investment in combination with the non rival nature of ideas, generates proportionally higher absolute cost savings and hence benefits for the $R \& D$ sector. Thus, a change in the level of $R \& D$ hence in the overall rate of technical change, reinforces itself through its impact on economic lifetime.

The policy recommendations that can be drawn from the experiments above are quite general in nature. First, a tax on carbon based fuels may seem to be a good idea when emissions need to be reduced relatively sharply and quickly, because it invokes contemporaneous substitution reactions away from the more costly input. However, under the induced innovation 
hypothesis', this also redirects R\&D activity towards bypassing this tax barrier. This has the negative by-effect of drawing R\&D resources away from finding the only 'true' solution to the problem of reducing emissions, i.e. to improve the productivity of non-carbon based fuel technologies. These negative by-effects should thus be compensated, for instance through the recycling of the tax revenues as we have done in experiment 3 . This would make for a better transition from dirty to clean technologies, which is perfectly in accordance with the observation by Chakravorty and Tse (1998), who state that: "R\&D in renewable energy resources may play only a limited role in the short run, while creating the basis for a transition to a sustainable energy economy over the longer time horizon". 


\section{References}

- Aghion, P. and Howitt, P., 1990, “A Model of Growth Through Creative Destruction”, Econometrica, Vol. 60 (2), pp. 323-351.

- Atkeson, A. and Kehoe, P.J., 1994 , "Models of Energy Use: Putty-Putty Versus Putty-Clay", NBER Working Paper 4833.

- Carraro, C. and Galeotti, M., 1997, "Economic Growth, International Competitivenss and Environmental Protection: R\&D and Innovation Strategies with the WARM Model", Energy Economics, Vol. 19 (1), pp. 2-28.

- Chakravorty, U. and Tse, K.-P. , 2000, “Transition from Fossil Fuels to Renewable Energy: Evidence from a Dynamic Simulation Model with Endogenous Resource Substitution”, FEEM Working Paper No. 99 .

- Dowlatabadi, H. , 1998, "Sensitivity of Climate Change Mitigation Estimates to Assumptions about Technical Change", Energy Economics, Vol. 20 , 5-6, , pp.473-493.

- Gerlagh, R. and Wietze, L. , 2003, "Induced Technological Change under Carbon Taxes“, Fondaziones Eni Enrico Mattei, Working Paper No. 2003-84.

- Grübler, A. and Messner, S. , 1998, “Technological Change and the Timing of Mitigation Measures”, Energy Economics, Vol. 20 (5-6), 495-512 .

- Huntington, H.G. and Weyant, J.P. , 2002, "Modeling Energy Markets and Climate Change Policy”, EMF OP 52, Energy Modeling Forum.

- Jones, Charles I., (2004) "The Shape of Production Functions and the Direction of Technical Change" http://elsa.berkeley.edu/ chad/cobb200.pdf - Kennedy, C. , 1964, "Induced Bias in Innovation and the Theory of Distribution" The Economic Journal, Vol. 74, pp. 541-547.

- Kooiman, P. and T. Kloek, Aggragation of micro markets in disequilibrium: theory and application to the Dutch labour market, 1948-1975, Working Paper, Erasmus University Rotterdam, 1979.

- Mabey, N., Hall, S., Smith, C. and Gupta, S. , 1997, "Argument in the Greenhouse, the International Economics of Controlling Global Warming," Routledge, London.

- Phelps, E.S. , 1962, “The New View of Investment: A Neoclassical Analysis”, Quarterly Journal of Economics, Vol. 76, pp 20. 
- Popp, D. , 2001, “Induced Innovation \& Energy Prices” NBER, Working Paper No. 8284, www.nber.org/papers/w8284.

- Romer, P.M. , 1990, “Endogenous Technological Change”, Journal of Political Economy, Vol. 98 , 5, pp.71-102 .

- Ruttan, V.W. , 2001, “Technology, Growth, and Development: An Induced Innovation Perspective", Oxford University Press.

- Sneessens, H. and J.H. Drèze, A discussion of Belgian unemployment, Combining Traditional Concepts and Disequilibrium Econometrics, Economica 53, 1986, pp. 89-119.

- Solow, R., 2000, “Growth Theory- An Exposition", 2nd edition, Oxford University Press.

- UN World Economic Situation and Prospects 2005, (Chapter IV Regional developments and outlook) United Nations New York, 2005. http://www.un.org/esa/policy/wess/wesp2005files/wesp2005.pdf

-UNEP 2004 ANNUAL REPORT. United Nations Environment Programme http://www.unep.org/AnnualReport/2004/01\%20AR\%20LAYOUT\%20PART \%202.pdf

- Van Zon, Adriaan, 1994, 'RUM: a Simple Recursive Update Model Providing a Condensed Representation of a Putty-Semi-Putty Vintage Model', MERIT Research Memorandum, RM94-002.

- Van Zon, Adriaan, Fortune, Emmanuelle and Kronenberg, Tobias, 2003, How to Sow and Reap as You Go: a Simple Model of Cyclical Endogenous Growth, MERIT Research Memorandum, RM2003-026.

- Van Zon, Adriaan, 2005, "Vintage Modelling for Dummies using the PuttyPractically-Clay Approach", MERIT Research Memorandum 2005-005.

- Wan, H.Y.Jr. , 1971, “Economic Growth” , Harcourt Brace Jovanovich. 